\title{
Cell proliferation controls body size growth, tentacle morphogenesis, and regeneration in hydrozoan jellyfish Cladonema pacificum
}

\author{
Sosuke Fujita ${ }^{1}$, Erina Kuranaga ${ }^{1}$, Yuichiro Nakajima ${ }^{\text {Corresp. } 1,2}$ \\ ${ }^{1}$ Graduate School of Life Sciences, Tohoku University, Sendai, Japan \\ 2 Frontier Research Institute for Interdisciplinary Sciences, Tohoku University, Sendai, Japan \\ Corresponding Author: Yuichiro Nakajima \\ Email address: yuichiro.nakajima.d2@tohoku.ac.jp
}

Jellyfish have existed on the earth for around six hundred million years and have evolved in response to environmental changes. Hydrozoan jellyfish, members of phylum Cnidaria, exist in multiple life stages, including planula larvae, vegetatively-propagating polyps, and sexually-reproducing medusae. Although free-swimming medusae display complex morphology and exhibit increase in body size and regenerative ability, their underlying cellular mechanisms are poorly understood. Here, we investigate the roles of cell proliferation in body-size growth, appendage morphogenesis, and regeneration using Cladonema pacificum as a hydrozoan jellyfish model. By examining the distribution of $\mathrm{S}$ phase cells and mitotic cells, we revealed spatially distinct proliferating cell populations in medusae, uniform cell proliferation in the umbrella, and clustered cell proliferation in tentacles. Blocking cell proliferation by hydroxyurea caused inhibition of body size growth and defects in tentacle branching, nematocyte differentiation, and regeneration. Local cell proliferation in tentacle bulbs is observed in medusae of two other hydrozoan species, Cytaeis uchidae and Rathkea octopunctata, indicating that it may be a conserved feature among hydrozoan jellyfish. Altogether, our results suggest that hydrozoan medusae possess actively proliferating cells and provide experimental evidence regarding the role of cell proliferation in body-size control, tentacle morphogenesis, and regeneration. 


\title{
2 Cell proliferation controls body size growth, tentacle
}

3 morphogenesis, and regeneration in hydrozoan

4

5

6

\section{jellyfish Cladonema pacificum}

\author{
${ }^{1}$ Sosuke Fujita, ${ }^{1}$ Erina Kuranaga, and ${ }^{1,2}$ Yu-ichiro Nakajima \\ ${ }^{1}$ Graduate School of Life Sciences, Tohoku University, Sendai, Japan \\ ${ }^{2}$ Frontier Research Institute for Interdisciplinary Sciences, Tohoku University, Sendai, \\ Japan
}

Corresponding Author: Yu-ichiro Nakajima

Address: 6-3 Aoba, Aramaki-Aza, Aoba-ku, Sendai, 980-8578,

Email address: yuichiro.nakajima.d2@tohoku.ac.jp

\section{Abstract}

Jellyfish have existed on the earth for around six hundred million years and have evolved in response to environmental changes. Hydrozoan jellyfish, members of phylum Cnidaria, exist in multiple life stages, including planula larvae, vegetatively-propagating polyps, and sexually-reproducing medusae. Although free-swimming medusae display complex morphology and exhibit increase in body size and regenerative ability, their underlying cellular mechanisms are poorly understood. Here, we investigate the roles of cell proliferation in body-size growth, appendage morphogenesis, and regeneration using Cladonema pacificum as a hydrozoan jellyfish model. By examining the distribution of $\mathrm{S}$ phase cells and mitotic cells, we revealed spatially distinct proliferating cell populations in medusae, uniform cell proliferation in the umbrella, and clustered cell proliferation in tentacles. Blocking cell proliferation by hydroxyurea caused inhibition of body size growth and defects in tentacle branching, nematocyte differentiation, and regeneration. Local cell proliferation in tentacle bulbs is observed in medusae of two other hydrozoan species, Cytaeis uchidae and Rathkea octopunctata, indicating that it may be a conserved feature among hydrozoan jellyfish. Altogether, our results suggest 
33 that hydrozoan medusae possess actively proliferating cells and provide experimental evidence regarding the role of cell proliferation in body-size control, tentacle morphogenesis, and regeneration.

\section{Introduction}

Cell proliferation lies at the core of controlling cell number in Metazoa and thus contributes to the growth and the maintenance of animal body and organs (Leevers \& McNeill 2005; Penzo-Mendez \& Stanger 2015). During development, cell proliferation plays a critical role in body-size increase by adding cells into tissue layers, and it further generates cellular resources for different cell types by multiplying progenitors (Gillies \& Cabernard 2011; Hardwick et al. 2015). Later in adults, proliferating cells are required for physiological cell turnover and for the replacement of damaged cells after tissue . . injury (King \& Newmark 2012; Pellettieri \& Sanchez Alvarado 2007). These roles of cell proliferation in multicellularity must be conserved throughout evolution: indeed, sponges, one of the earliest metazoan organisms, have acquired mechanisms to allow cell turnover by controlling proliferative capacities (Alexander et al. 2014; Kahn \& Leys 2016).

As the sister group of bilaterians and early-branching metazoans, cnidarians have been studied as a model to understand evolutionary development (Genikhovich \& Technau 2017). Cnidarians are diploblastic and radially symmetric animals that include diverse species such as corals, sea anemones, hydroids, and jellyfish (Technau \& Steele 2011). During the embryonic development of the sea anemone Nematostella vectensis, cell proliferation is coordinated with epithelial organization and is involved in tentacle development (Fritz et al. 2013; Ragkousi et al. 2017). Cnidarians are also known for their regenerative abilities: for instance, Hydra polyps have been used for a century to investigate mechanisms of metazoan regeneration (Fujisawa 2003; Galliot \& Schmid 2002). The basal head regeneration of Hydra relies on cell proliferation triggered by dying cells (Chera et al. 2009b; Galliot \& Chera 2010). Hydractinia polyps regenerate through cell proliferation and the migration of stem-like cells (Bradshaw et al. 2015; Gahan et al. 2016). Although much has been learned about mechanisms controlling embryogenesis and growth during regeneration, it is unclear how cnidarians 
65

66

67

68

69

70

71

72

73

74

75

76

77

78

79

80

81

82

83

84

85

86

87

88

89

90

91

92

93

94

95

integrate cell proliferation to control their body size and maintain tissue homeostasis under normal physiological conditions.

Among cnidarians, hydrozoan jellyfish have a complex life cycle including planula larvae, sessile polyps, and free-swimming medusae. While polyps undergo asexual reproduction to grow vegetatively, medusae generate gametes to perform sexual reproduction. Despite the limited life span compared to the long-lived or possibly immortal polyps, the size of medusae increases dramatically (Hansson 1997; Miyake et al. 1997). Furthermore, medusae maintain their regenerative capacity for missing body parts by integrating dedifferentiation and transdifferentiation (Schmid \& Alder 1984; Schmid et al. 1988; Schmid et al. 1982). Recent studies using the hydrozoan jellyfish Clytia hemisphaerica have provided mechanistic insights into embryogenesis, nematogenesis, and egg maturation (Denker et al. 2008; Momose et al. 2008; Quiroga Artigas et al. 2018). However, little is known about the mechanism that controls body size growth in medusae. It is also unclear whether cell proliferation is required for tentacle morphogenesis and regeneration of hydrozoan jellyfish.

The hydrozoan jellyfish Cladonema is an emerging model, with easy lab maintenance and a high spawning rate, that is suitable for studying diverse aspects of biology including development, regeneration, and physiology (Fujiki et al. 2019; Graziussi et al. 2012; Suga et al. 2010; Takeda et al. 2018b; Weber 1981). Cladonema is characterized by small-sized medusae with branched tentacles. Using specialized adhesive tentacles, Cladonema can adhere to different substrata, such as seaweed, in the field. The species Cladonema pacificum, originally found along coastal areas in Japan, have nine main tentacles with a stereotyped branching pattern (Fig. 1A-C). During the Cladonema medusa's maturation, body size increases, and each main tentacle grows and exhibits branching morphology (Fujiki et al. 2019), providing an ideal system to dissect the cellular mechanisms associated with jellyfish growth and morphogenesis.

In this study, we investigate the role of cell proliferation in medusa growth and morphogenesis, using Cladonema pacificum as a model of hydrozoan jellyfish. We show that cell proliferation occurs evenly across the medusa body, including the umbrella and manubrium, with the exception of the tentacles, where cell proliferation is 
96

97

98

99

100

101

102

103

104

105

106

107

108

109

110

111

112

113

114

115

116

117

118

119

120

121

122

123

124

125

126

spatially clustered. Blocking cell-cycle progression with a pharmacological assay inhibits the increase of body size, tentacle branching, and nematocyte differentiation, which suggests that cell proliferation is necessary for growth and tentacle morphogenesis. We further show that cell proliferation is required for tentacle regeneration in Cladonema medusae. Our findings reveal cell proliferation's critical roles in the development and maintenance of the Cladonema body and appendages and provide a basis for understanding growth-control mechanisms in hydrozoan jellyfish.

\section{Materials \& Methods}

\section{Animal cultures}

We used Cladonema pacificum (strains 6W and UN2) (Fig. 1-5, S1-3), Cytaeis uchidae (strain +17) (Fig. 6) and Rathkea octopunctata (strain MF-1) (Fig. 6) medusae for this research. The medusae were cultured in plastic cups (V-type container, V-7 and V-8, AS ONE) at $20^{\circ} \mathrm{C}$ (Cladonema and Cytaeis) or $4^{\circ} \mathrm{C}$ (Rathkea), and their polyps were maintained in the cups $(\mathrm{V}-7)$ at $20^{\circ} \mathrm{C}$ or $4^{\circ} \mathrm{C}$ in darkness. Vietnamese brine shrimp (A\&A Marine LLC) were fed to medusae and polyps every other day ad libitum, with water renewed immediately after feeding. Artificial sea water (ASW) was prepared by SEA LIFE (Marin Tech, Tokyo). Pictures of medusae were taken through a LEICA S8APO microscope with a Nikon digital camera (D5600).

\section{Immunofluorescence}

The medusae were anesthetized with $7 \% \mathrm{MgCl}_{2}$ in $\mathrm{ASW}$ for $10 \mathrm{~min}$ and fixed $4 \%$ paraformaldehyde (PFA) in ASW for $1 \mathrm{hr}$. After fixation, the samples were rinsed in $1 \mathrm{x}$ PBS and washed 3 times (10 min each) in PBS containing $0.1 \%$ Triton X-100 (0.1\% PBT). The samples were incubated in primary antibodies in $0.1 \%$ PBT overnight at $4{ }^{\circ} \mathrm{C}$. The antibodies used were rabbit anti-Phospho-Histone H3 (Ser10) (1:500; Upstate, 06570) and mouse anti-a-Tubulin (1:500; SIGMA, T6199). After the primary antibody incubation, the samples were washed 3 times (10 min each) in $0.1 \%$ PBT and incubated in secondary antibodies (1:500; ALEXA FLUOR Goat anti-mouse IgG, ALEXA FLUOR Goat anti-rabbit IgG, Life Technologies) and Hoechst 33342 (1:250; Thermo Scientific) 
127 in $0.1 \%$ PBT for $1 \mathrm{hr}$ in dark. After 4 washes (10 min each) in $0.1 \%$ PBT, the samples 128 were mounted on slides with $70 \%$ glycerol. Confocal images were collected through 129 Leica SP8 or SP5 confocal microscopes. Z-stack images were performed using 130 ImageJ/Fiji software.

131

132 EdU labeling

133 The medusae were incubated with $20 \mu \mathrm{M}$ EdU (EdU kit; Invitrogen, 1836341) in ASW 134 for $24 \mathrm{hr}$ (Figs. 1-3 and 6) or $150 \mu \mathrm{M}$ for $1 \mathrm{hr}$ (Fig. S1). After EdU treatment, the 135 medusae were anesthetized with $7 \% \mathrm{MgCl}_{2}$ in $\mathrm{ASW}$ for 10 min and fixed $4 \%$ paraformaldehyde (PFA) in ASW for $1 \mathrm{hr}$. After fixation, the samples were rinsed in $1 \mathrm{x}$ PBS and washed 3 times (10 min each) in $0.1 \%$ PBT. The samples were incubated with a EdU reaction cocktail ( $1 \mathrm{x}$ reaction buffer, $\mathrm{CuSO}_{4}$, Alexa Fluor azide, and $1 \mathrm{x}$ reaction buffer additive; all included in EdU kit; Invitrogen, 1836341) for 30 min in the dark. After the EdU reaction, the samples were washed 3 times (10 min each) in $0.1 \%$ PBT and Hoechst 33342 (1:250; Thermo Scientific) in 0.1\% PBT for $1 \mathrm{hr}$ in dark. The samples were washed 4 times (10 min each) in $0.1 \%$ PBT and were mounted on slides with $70 \%$ glycerol.

Hydroxyurea treatment

The live medusae were incubated with $10 \mathrm{mM}$ hydroxyurea (HU) (Wako, LKP3349) in ASW (ASW only for control) (Fig. 3-5, S3). HU incubation was continued for a maximum of 9 days. Medusae were fed every other day, and HU solution or ASW was renewed after feeding. The medusae treated with $\mathrm{HU}$ were able to ingest prey like controls, demonstrating that $\mathrm{HU}$ treatment had no effect on feeding behavior (Fig S3A, B).

\section{Measurement of umbrella size and tentacle length}

Pictures of medusae were taken with a Nikon D5600, and umbrella size was measured using polygon selections with Image J software (Fig. $3 \mathrm{H})$. We measured the length and width of medusae under the microscope using an ocular micrometer and multiplied the length and width to generate a value for umbrella size (Fig. 3M). Tentacle length was measured daily under the microscope with an ocular micrometer (Fig. $5 \mathrm{H}$ ). 


\section{DAPI poly-y-glutamate staining}

160 This protocol was adapted from (Szczepanek et al. 2002): The medusae were

161

162

163

164

165

166

167

168

169

170

171

172

173

174

175

176

177

178

179

180

181

182

183

184

185

186

187

188

anesthetized with $7 \% \mathrm{MgCl}_{2}$ in ASW for 10 min and fixed with 4\% PFA in ASW for $1 \mathrm{hr}$. After fixation, the samples were rinsed in 1x PBS and washed 3 times (10 min each) in $0.1 \%$ PBT. The samples were incubated in DAPI (1:500; Polysciences, Inc.) in PBT for 60 min. After the DAPI incubation, samples were washed 4 times (10 min each) in PBT and mounted on slides with $70 \%$ glycerol in DW. Samples were scanned with a combination of $488 \mathrm{~nm}$ excitation and $555 \mathrm{~nm}$ emission filter using either Leica SP8 or SP5 confocal microscopes. Using ImageJ, we performed Z-stacks and counted nematocysts. Empty nematocysts were counted manually.

\section{Dissection of tentacles for regeneration}

Tentacles' basal sides were dissected with small scissors, leaving the tentacle bulbs intact. Amputated medusae were fed every other day.

\section{Statistical test}

An unpaired two-tailed $t$-test was performed on the data shown in Figure 3, 4, and 5.

\section{Average Nearest Neighbor Distance (Spatial Statistics)}

We performed statistical analysis for the proliferating cells' distribution in umbrellas and tentacles by applying the Nearest Neighbor Distance test to EdU positive cells. Here, we used the images of 1 day old medusae that had been incubated with EdU 150uM for $1 \mathrm{hr}$. This analysis was applied to the umbrella area, except for tentacle bulb and manubrium, while the same analysis was applied to the entire main tentacle. The area (S), the signal number (N), and nearest neighbor distance (NND) in analyzed areas were obtained using ImageJ/ Fiji. The average of NND (W), the expectation value of W $(E[W])$, and the normalized average of NND ( $w=W / E[W])$ were calculated. In this analysis, w>1 means that EdU signals are distributed uniformly or randomly. In contrast, $w<1$ means that EdU signals are distributed clustered or randomly. The spatial distribution of EdU signals were determined by Z score. 


\section{Results}

\section{Cell proliferation patterns in the medusa Cladonema pacificum}

192 To understand the spatial pattern of cell proliferation in Cladonema medusa, we 193 performed 5-ethynyl-2'-deoxyuridine (EdU) staining, which labels S-phase or the 194 former S-phase cells (Salic \& Mitchison 2008). Given that Cladonema medusa dramatically increases in size and exhibits tentacle branching during development (Fig. $1 \mathrm{~A}-1 \mathrm{C})$, distribution of proliferating cells could change throughout maturation. We thus investigated cell proliferation patterns in both young (day 1 ) and sexually mature (day 45) medusae.

In young medusae, EdU-positive cells were broadly detected in the whole medusa body including the umbrella, the manubrium (a supporting organ of the oral in

201

202

203

204

205

206

207

208

209

210

211

212

213

214

215

216

217

218

219 medusae), and the tentacles regardless of the incubating time of EdU (Fig. 1D-1K and $1 \mathrm{~N}-\mathrm{O}$, EdU: $20 \mu \mathrm{M}$ for 24 hour; Fig. S1, EdU: $150 \mu \mathrm{M}$ for 1 hour). While small numbers of EdU positive cells were detected in the manubrium (Fig. 1F and 1G), EdU positive cells were uniformly distributed in the umbrella (Average Nearest Neighbor Distance: uniform, $n=6 / 7$, random, $n=1 / 7$; Table S1), especially in the exumbrella region (Fig. $1 \mathrm{H}$ $1 \mathrm{~K})$. By contrast, in the tentacles, large numbers of EdU positive cells were identified as clustered (Fig. $1 \mathrm{~N}$ and 10; Nearest Neighbor Distance: clustered, $n=7 / 7$, Table S1). We further confirmed that these EdU-positive cells were proliferating cells using the mitotic marker, anti-Phospho-Histone 3 (PH3) antibody. PH3-positive cells were detected in both the umbrella and the tentacle bulbs (Fig. $1 \mathrm{~L}$ and $1 \mathrm{P}$ ). In tentacles, mitotic cells were primarily detected in the ectoderm (Fig 1P and Fig. S2), whereas in the umbrella, proliferating cells were located in the exumbrella, which was confirmed by the presence of mitotic spindles, detected with an anti- $\alpha$ Tubulin antibody in PH3-positive cells (Fig. $1 \mathrm{M})$.

As observed in young medusae, EdU-positive cells were broadly detected in the entire body of mature medusae (Fig. 2). In the umbrella, EdU-positive cells were more often located in the exumbrella than in the subumbrella, which is similar to the case of young medusae (Fig. 2A-2D). By contrast, in tentacles, EdU-positive cells were restricted to their base, called the tentacle bulb, where two apparent 'clusters' are 
220 located on both sides of the bulb (Fig. 2E and 2F). These clusters were also observed in 221 the tentacle bulb of young medusae (Fig. $1 \mathrm{~N}$ and 10), suggesting that tentacle bulbs 222 may behave as a proliferation zone throughout the medusa stage. Interestingly, in the 223 manubrium of matured medusae, large numbers of EdU-positive cells were detected 224 (Fig. 2G and $2 \mathrm{H}$ ). This result likely reflects the presence of germ cells that are produced 225 in the manubrium, a feature of the sexually matured Cladonema medusa (Takeda et al. 226 2018b).

Altogether, our results suggest that cell proliferation may occur uniformly in the 228 medusa umbrella, while a subset of cell proliferation could occur locally in tentacles. Based on these observations, we hypothesized that uniform cell proliferation may control body size growth and tissue homeostasis while clustered cell proliferation in tentacles may contribute to tentacle morphogenesis.

Cell proliferation is necessary for the control of body size

Animal body size increases upon intake of nutrition because nutrition influences cell proliferation and cell growth (Bohnsack \& Hirschi 2004). We first monitored the body size of juvenile medusae by focusing on the size of their umbrella because the umbrella grows in direct proportion with whole body size. Under normal feeding conditions, the medusa umbrella size increased dramatically by $54.8 \%$, from $0.62 \pm 0.02 \mathrm{~mm}^{2}$ to $0.96 \pm 0.02 \mathrm{~mm}^{2}$ during the first 24 hours, with a subsequent minor increase observed over the following 5 days $\left(0.98 \pm 0.03 \mathrm{~mm}^{2}\right)$ (Fig. $\left.3 \mathrm{~A}-3 \mathrm{C}\right)$. By contrast, under starved conditions, the size of medusa umbrella did not increase, compared to controls, and rather gradually decreased over the following 5 days (Fig. 3C). Moreover, fewer EdU positive cells were detected in the starved medusae than in fed controls (Fig. 3D-3H; Control: $1240.6 \pm 214.3$, Starved: $433.6 \pm 133, t(8)=3.194,{ }^{*} p<0.05(p=0.0127)$, suggesting that, at the cellular level, nutrition affects cell proliferation in medusae. These results indicate that body-size growth in juvenile medusae depends on available nutrition.

To test the hypothesis that uniform cell proliferation in medusae contributes to body-size increase, we performed a pharmacological assay to block cell-cycle progression using hydroxyurea, a cell-cycle inhibitor that causes G1 arrest (Koc et al. 2004). Under hydroxyurea treatment, $S$ phase cells detected by EdU staining 
251 disappeared from the medusa body (Fig. 3I-3L). By tracking the size of umbrella, we

252 found that hydroxyurea-treated medusae did not exhibit the size increase that was

253 observed in controls (Fig. 3M). Together, these results suggest that cell-cycle

254 progression affects body size in Cladonema medusae.

255

256 Cell proliferation is necessary for tentacle morphogenesis

257 In Clytia hemisphaerica, another hydrozoan jellyfish, stem-like cells or progenitors are 258 proposed to exist in tentacle bulbs (Denker et al. 2008). The clustered or local cell

259 proliferation observed in tentacles, including those in the bulb, of the Cladonema

260 medusa may reflect such stem or progenitor cell populations (Fig. 1N-1O, 2E-2F and

261 S1D). Furthermore, many EdU positive cells were frequently detected in small branched

262 tentacles, which were the most recently branched (Fig. 3D-3E and 3I-3J). To test the

263 hypothesis that local cell proliferation in tentacles contributes to tentacle

264 morphogenesis, we first focused on tentacle branching. Although the initial tentacles

265 have one branch in juvenile medusae, the number of branches gradually increases 266 during medusa maturation (Fujiki et al. 2019). In our normal feeding condition, the 267 branching number reached approximately three (2.98 \pm 0.05 per tentacle) by day 9 (Fig.

$2684 \mathrm{~A}$ and $4 \mathrm{C}$ ). By contrast, when cell proliferation was blocked with hydroxyurea, none of 269 the medusae exhibited the typical increase in branched tentacles; rather, all maintained 270 only one branch (Fig. 4B and 4C). Importantly, upon removal of hydroxyurea, these 271 animals showed an increase in tentacle branching similar to controls, suggesting that 272 the effects of the drug treatment are reversible (Fig. S3C). Combined, these results 273 point to cell proliferation in tentacles as a necessary component for normal tentacle 274 branching.

275 Cnidarian tentacles have nematocysts, organelles specific to the cnidarian 276 phylum that are utilized for food capture and defense against predators (Kass-Simon \& 277 Scappaticci 2002). In Clytia hemisphaerica, stem-like cells or progenitors in tentacle 278 bulbs seem to supply nematocysts at the tips of tentacles via cell proliferation, migration 279 to the tip, and differentiation (Denker et al. 2008). This evidence raises the possibility 280 that cell proliferation also controls nematocyte development or nematogenesis in 281 hydrozoan jellyfish. To monitor nematocytes in Cladonema tentacles, we utilized DAPI, 
282 a nuclear staining dye that can label poly- $\gamma$-glutamate synthesized in the nematocyst 283 wall (Szczepanek et al. 2002). Using poly-Y-glutamate staining, we discovered

284

285

286

287

288

289

290

291

292

293

294

295

296

297

298

299

300

301

302

303

304

305

306

307

308

309

310

311

312 nematocyte size variations ranging from $2 \mu \mathrm{m}^{2}-110 \mu \mathrm{m}^{2}$ (Fig. 4D-4G). We also found that some of the nematocysts were empty, suggesting that such nematocytes had been depleted (Fig. 4D-4G).

In order to investigate whether cell proliferation in tentacle also contributes to nematocyte maturation, we examined the emptiness of nematocytes after cell-cycle blocking with hydroxyurea. We detected that the proportion of the empty nematocysts was higher in the medusae with hydroxyurea treatment than in controls $(\mathrm{HU}+$ : 11.4 $\pm 2.0 \%$; $\mathrm{HU}-:$ 19.7 $\pm 2.0 \%$, Fig. $4 \mathrm{D}-4 \mathrm{G}$ and $4 \mathrm{H}$ ). This result indicates that even after discharge, nematocytes are still actively supplied by progenitor cell proliferation and that this refill is prevented when cell proliferation is blocked. Taken together, our data suggest that cell proliferation in tentacle plays an important role in both tentacle branching and nematogenesis.

\section{Cell proliferation is necessary for tentacle regeneration}

Cnidarians are known to have a high regenerative capacity (Galliot \& Schmid 2002; Holstein et al. 2003), and the hydrozoan jellyfish Cladonema species exemplifies this typical regenerative ability (Weber 1981). Given the localization of proliferative cells in the tentacle bulb of matured Cladonema medusae (Fig. 2E and 2F), we decided to investigate the nature of tentacle regeneration. After dissecting tentacles at their base, we monitored the process of tentacle regeneration (Fig. 5A-5D). During the first 24 hours, wound healing occurred at the dissected area (Fig. 5B). Subsequently, the tip of tentacle became elongated and started branching on day 2 (Fig. 5C). At day 4, fully branched tentacles were observed (Fig. 5D), suggesting that tentacle regeneration may follow normal tentacle morphogenesis after elongation.

To examine the initial stage of tentacle regeneration, we examined the distribution of proliferating cells using $\mathrm{PH} 3$ staining to visualize mitotic cells. While dividing cells were frequently observed near the amputated area, mitotic cells were dispersed in uncut control tentacle bulbs (Fig. $5 \mathrm{E}$ and $5 \mathrm{~F}$ ). We quantified the number of $\mathrm{PH} 3$-positive cells present in the tentacle bulbs and found a significant increase in PH3- 
313 positive cells in the tentacle bulbs of amputee medusae, compared to controls (Fig. 5G).

314 These observations indicate that initial regenerative responses accompany the active 315 increase of cell proliferation in tentacle bulbs.

316 In order to test the role of cell proliferation in tentacle regeneration, we blocked

317 cell-cycle progression using hydroxyurea after dissection and monitored the length of

318 regenerating tentacles. While the tentacles continued to elongate from the bulb

319 structure after dissection in controls, tentacles in animals treated with hydroxyurea were

320 not able to elongate despite displaying normal wound healing (Fig. $5 \mathrm{H}$ ). These results

321 demonstrate that cell proliferation in tentacle bulbs is required for proper tentacle

322 regeneration.

323

324 Cell proliferation patterns across different hydrozoan jellyfish

325 Hydrozoan jellyfish constitute the most broadly varied class of cnidarian jellyfish with

326 approximately 1,150 species worldwide featuring highly diverse morphological and

327 physiological characteristics (Cartwright \& Nawrocki 2010; Schuchert 2019). For

328 instance, Cytaeis uchidae has four tentacles, and their polyps live exclusively on one

329 type of shell: Niotha livescens (Takeda et al. 2018a; Takeda et al. 2013). Another

330 species, Rathkea octopunctata, has eight grouped-tentacles, and their juvenile

331 medusae asexually produce medusae that grow out of the manubrium (Berrill 1952;

332 Schuchert 2007).

333 To gain insight into the conserved and diversified nature of cell proliferation in

334 hydrozoan jellyfish, we investigated the spatial pattern of cell proliferation in Cytaeis and

335 Rathkea medusae. In Cytaeis medusa, EdU-positive cells were observed in manubrium, 336 tentacle bulbs, and at the top of the umbrella (Fig. 6A and 6B). PH3-positive cells were

337 also detected in the same regions, suggesting that proliferating cells in Cytaeis are

338 distributed in a pattern similar to that observed in Cladonema, although there are some

339 discrepancies (Fig. 6C and 6D). By contrast, in Rathkea octopunctata, EdU-positive

340 cells and $\mathrm{PH} 3-$ positive cells were mostly restricted to the manubrium and tentacle bulbs

341 (Fig. 6E-H). Of note, proliferating cells were frequently detected in the medusa buds that

342 grew out of the manubrium (Fig. 6E-6G), which may reflect asexual reproduction in

343 Rathkea medusae. These results suggest that cell proliferation may occur in tentacle 
344 bulbs across hydrozoan medusae commonly, while cell proliferation patterns may vary

345 in a species-specific manner with physiology.

346

347 Discussion

348 In this study, we show that the body size of Cladonema medusae is influenced by cell 349 proliferation following uptake of nutrition. Without nutrition and under the blocking of 350 cell-cycle progression, body-size increase is inhibited (Fig. 3). Intriguingly, despite the 351 significant differences between fed and starved animals and between hydroxyurea352 treated and -untreated animals, the body size of Cladonema medusae increases during 353 the first 24 hours regardless of condition (Fig. 3). A similar body size increase under 354 starved conditions is also reported in the medusa of Cladonema californicum Hyman 355 (Costello 1998). These observations can be explained by cell growth via protein 356 synthesis (Schiaffino et al. 2013) or accretionary growth, in which cells secrete extracellular matrix to increase extracellular regions, as has been suggested in the 358 growth of cartilage and bone (Karsenty et al. 2009; Wang et al. 2014). Given the large amount of collagen that jellyfish contain (Khong et al. 2016; Miura \& Kimura 1985), extracellular matrix may increase their size during the initial growth of juvenile medusae. Another interesting feature we observed is that the body size of the starved 362 medusae gradually decreases after 24 hours (Fig. 3C). Similarly, upon starvation, Hydra polyps cease asexual budding and decrease their size (Buzgariu et al. 2008; Chera et al. 2009a), suggesting that cnidarian animals are sensitive to nutrition availability and adapt to metabolic changes. At the organ and tissue level, such size reduction can occur via autophagy or cell death during starvation in diverse phyla (Jeschke et al. 2000; O'Brien et al. 2011; Thongrod et al. 2018; Tracy \& Baehrecke 2013). Cnidarians thus may utilize similar mechanisms to reduce cell size and/or cell number to adjust their body size in response to environmental changes. Molecularly, TOR and Hippo signaling are conserved machinery that control organ size, and, as such, these molecules may also play an important role in cnidarian growth control (Coste et al. 2016; Ikmi et al. 2014; Loewith \& Hall 2011; van Dam et al. 2011).

Hydrozoan animals are known to possess interstitial stem cell populations, called 374 i-cells. In Hydra and Hydractinia polyps, i-cells are localized to the body column, mostly 
375 in ectoderm, and have the potential to differentiate into several cell types including 376 nematocytes, nerve cells, and gametes (Gold \& Jacobs 2013; Hemmrich et al. 2012;

377 Hobmayer et al. 2012; Kunzel et al. 2010; Muller et al. 2004). By contrast, the current

378 understanding of the localization and roles of stem-like cells or i-cells in hydrozoan 379 jellyfish are limited (Leclere et al. 2012). In Cladonema medusa, although mitotic cells 380 are localized in the ectoderm, clusters of proliferative cells are distributed throughout the 381 tentacle, except for the tip region (Fig. S1 and Fig.S2). This finding contrasts with the 382 case of Clytia, where i-cells are primarily clustered in the tentacle bulb (Denker et al. 383 2008), implying that the i-cells or progenitors of Cladonema may be more broadly 384 385 386 387 localized. Our pharmacological experiments confirmed that cell proliferation contributes to tentacle branching, nematogenesis, and tentacle regeneration in Cladonema (Fig. 4 and Fig. 5), suggesting that these proliferative cells may behave as progenitors or stemlike cells. We further found similar distribution of proliferative cells in tentacle bulbs of Cytaeis uchidae and Rathkea octopunctata (Fig. 6). Together, these results suggest that the distribution of proliferative cells in tentacle bulbs are widely conserved in hydrozoan jellyfish, while such cells might exist in other tissue to allow body-size increase and species-specific life styles.

\section{Conclusions}

394 This study reveals the spatial patterns of cell proliferation during the growth and 395 morphogenesis of the medusae Cladonema pacificum at different stages of maturation. Using a cell-cycle inhibitor assay, we show that uniform cell proliferation in the umbrella is responsible for overall body-size increase, while clustered cell proliferation in tentacles contributes to branching morphogenesis, nematocyte differentiation, and regeneration. We further provide evidence for conserved and species-specific cell proliferation patterns in hydrozoan jellyfish by examining two other hydrozoan species, Cytaeis uchidae and Rathkea octopunctata. The clustered cell proliferation in the tentacle bulbs of these hydrozoan medusae evinces the possibility of a progenitor or stem-like cell population, although its existence will need to be confirmed in future studies. On the whole, our work establishes the basis for understanding the cellular mechanisms of jellyfish growth and 405 homeostasis, which will facilitate future work to dissect the molecular mechanisms 
406 underlying these processes.

407

408

409

\section{Acknowledgements}

410

411

412

413

414

415

416

417

418

419

420

421

422

423

424

425

426

427

428

429

430

431

432

433

434

435

436

437

438

439

440

441

442

443

We thank R. Deguchi (Miyagi Education Univ. Japan) for sharing jellyfish species and helpful discussion. We thank S. Tasaki for helping statistical analyses. We thank $\mathrm{H}$.

Takashima for technical assistance. We thank Kuranaga lab members for discussion.

\section{References}

Alexander BE, Liebrand K, Osinga R, van der Geest HG, Admiraal W, Cleutjens JP, Schutte B, Verheyen F, Ribes M, van Loon E, and de Goeij JM. 2014. Cell turnover and detritus production in marine sponges from tropical and temperate benthic ecosystems. PLoS One 9:e109486. 10.1371/journal.pone.0109486

Berrill NJ. 1952. Growth and Form in Gymnoblastic Hydroids .2. Sexual and Asexual Reproduction in Rathkea .3. Hydranth and Gonophore Development in Pennaria and Acaulis .4. Relative Growth in Eudendrium. Journal of Morphology 90:1-32. DOI 10.1002/jmor.1050900102

Bohnsack BL, and Hirschi KK. 2004. Nutrient regulation of cell cycle progression. Annu Rev Nutr 24:433-453. 10.1146/annurev.nutr.23.011702.073203

Bradshaw B, Thompson K, and Frank U. 2015. Distinct mechanisms underlie oral vs aboral regeneration in the cnidarian Hydractinia echinata. Elife 4:e05506. 10.7554 /eLife.05506

Buzgariu W, Chera S, and Galliot B. 2008. Methods to investigate autophagy during starvation and regeneration in hydra. Methods Enzymol 451:409-437. 10.1016/S0076-6879(08)03226-6

Cartwright P, and Nawrocki AM. 2010. Character evolution in Hydrozoa (phylum Cnidaria). Integr Comp Biol 50:456-472. 10.1093/icb/icq089

Chera S, Buzgariu W, Ghila L, and Galliot B. 2009a. Autophagy in Hydra: a response to starvation and stress in early animal evolution. Biochim Biophys Acta 1793:14321443. 10.1016/j.bbamcr.2009.03.010

Chera S, Ghila L, Dobretz K, Wenger Y, Bauer C, Buzgariu W, Martinou JC, and Galliot B. $2009 \mathrm{~b}$. Apoptotic cells provide an unexpected source of Wnt3 signaling to drive hydra head regeneration. Dev Cell 17:279-289. 10.1016/j.devcel.2009.07.014

Coste A, Jager M, Chambon JP, and Manuel M. 2016. Comparative study of Hippo pathway genes in cellular conveyor belts of a ctenophore and a cnidarian. Evodevo 7:4. 10.1186/s13227-016-0041-y 
444

445

446

447

448

449

450

451

452

453

454

455

456

457

458

459

460

461

462

463

464

465

466

467

468

469

470

471

472

473

474

475

476

477

478

479

480

481

482

483

484

485

486

487

488

Costello J. 1998. Physiological response of the hydromedusa Cladonema californicum Hyman (Anthomedusa : Cladonemidae) to starvation and renewed feeding. Journal of Experimental Marine Biology and Ecology 225:13-28. Doi 10.1016/S00220981(97)00204-9

Denker E, Manuel M, Leclere L, Le Guyader H, and Rabet N. 2008. Ordered progression of nematogenesis from stem cells through differentiation stages in the tentacle bulb of Clytia hemisphaerica (Hydrozoa, Cnidaria). Dev Biol 315:99-113. 10.1016/j.ydbio.2007.12.023

Fritz AE, Ikmi A, Seidel C, Paulson A, and Gibson MC. 2013. Mechanisms of tentacle morphogenesis in the sea anemone Nematostella vectensis. Development 140:22122223. 10.1242/dev.088260

Fujiki A, Hou S, Nakamoto A, and Kumano G. 2019. Branching pattern and morphogenesis of medusa tentacles in the jellyfish Cladonema pacificum (Hydrozoa, Cnidaria). Zoological Letters 5. ARTN 12

10.1186/s40851-019-0124-4

Fujisawa T. 2003. Hydra regeneration and epitheliopeptides. Dev Dyn 226:182-189. 10.1002/dvdy.10221

Gahan JM, Bradshaw B, Flici H, and Frank U. 2016. The interstitial stem cells in Hydractinia and their role in regeneration. Curr Opin Genet Dev 40:65-73. 10.1016/j.gde.2016.06.006

Galliot B, and Chera S. 2010. The Hydra model: disclosing an apoptosis-driven generator of Wnt-based regeneration. Trends Cell Biol 20:514-523. 10.1016/j.tcb.2010.05.006

Galliot B, and Schmid V. 2002. Cnidarians as a model system for understanding evolution and regeneration. Int J Dev Biol 46:39-48.

Genikhovich G, and Technau U. 2017. On the evolution of bilaterality. Development 144:3392-3404. 10.1242/dev.141507

Gillies TE, and Cabernard C. 2011. Cell division orientation in animals. Curr Biol 21:R599609. 10.1016/j.cub.2011.06.055

Gold DA, and Jacobs DK. 2013. Stem cell dynamics in Cnidaria: are there unifying principles? Dev Genes Evol 223:53-66. 10.1007/s00427-012-0429-1

Graziussi DF, Suga H, Schmid V, and Gehring WJ. 2012. The "eyes absent" (eya) gene in the eye-bearing hydrozoan jellyfish Cladonema radiatum: conservation of the retinal determination network. J Exp Zool B Mol Dev Evol 318:257-267. 10.1002/jez.b.22442

Hansson LJ. 1997. Effect of temperature on growth rate of Aurelia aurita (Cnidaria, Scyphozoa) from Gullmarsfjorden, Sweden. Marine Ecology Progress Series 161:145153. DOI 10.3354/meps161145

Hardwick LJ, Ali FR, Azzarelli R, and Philpott A. 2015. Cell cycle regulation of proliferation versus differentiation in the central nervous system. Cell Tissue Res 359:187-200. 10.1007/s00441-014-1895-8

Hemmrich G, Khalturin K, Boehm AM, Puchert M, Anton-Erxleben F, Wittlieb J, Klostermeier UC, Rosenstiel P, Oberg HH, Domazet-Loso T, Sugimoto T, Niwa H, and Bosch TC. 2012. Molecular signatures of the three stem cell lineages in hydra and the emergence of stem cell function at the base of multicellularity. Molecular Biology and Evolution 29:3267-3280. 10.1093/molbev/mss134

PeerJ reviewing PDF | (2019:03:36215:1:1:REVIEW 5 Jul 2019) 
489

490

491

492

493

494

495

496

497

498

499

500

501

502

503

504

505

506

507

508

509

510

511

512

513

514

515

516

517

518

519

520

521

522

523

524

525

526

527

528

529

530

531

532

533

534

Hobmayer B, Jenewein M, Eder D, Eder MK, Glasauer S, Gufler S, Hartl M, and Salvenmoser W. 2012. Stemness in Hydra - a current perspective. Int J Dev Biol 56:509-517. $10.1387 /$ ijdb.113426bh

Holstein TW, Hobmayer E, and Technau U. 2003. Cnidarians: an evolutionarily conserved model system for regeneration? Dev Dyn 226:257-267. 10.1002/dvdy.10227

Ikmi A, Gaertner B, Seidel C, Srivastava M, Zeitlinger J, and Gibson MC. 2014. Molecular evolution of the Yap/Yorkie proto-oncogene and elucidation of its core transcriptional program. Molecular Biology and Evolution 31:1375-1390. 10.1093/molbev/msu071

Jeschke MG, Debroy MA, Wolf SE, Rajaraman S, and Thompson JC. 2000. Burn and starvation increase programmed cell death in small bowel epithelial cells. Dig Dis Sci 45:415-420.

Kahn AS, and Leys SP. 2016. The role of cell replacement in benthic-pelagic coupling by suspension feeders. R Soc Open Sci 3:160484. 10.1098/rsos.160484

Karsenty G, Kronenberg HM, and Settembre C. 2009. Genetic control of bone formation. Annu Rev Cell Dev Biol 25:629-648. 10.1146/annurev.cellbio.042308.113308

Kass-Simon G, and Scappaticci AA. 2002. The behavioral and developmental physiology of nematocysts. Canadian Journal of Zoology 80:1772-1794. 10.1139/Z02-135

Khong NM, Yusoff FM, Jamilah B, Basri M, Maznah I, Chan KW, and Nishikawa J. 2016. Nutritional composition and total collagen content of three commercially important edible jellyfish. Food Chem 196:953-960. 10.1016/j.foodchem.2015.09.094

King RS, and Newmark PA. 2012. The cell biology of regeneration. J Cell Biol 196:553-562. $10.1083 /$ jcb.201105099

Koc A, Wheeler LJ, Mathews CK, and Merrill GF. 2004. Hydroxyurea arrests DNA replication by a mechanism that preserves basal dNTP pools. J Biol Chem 279:223-230. 10.1074/jbc.M303952200

Kunzel T, Heiermann R, Frank U, Muller W, Tilmann W, Bause M, Nonn A, Helling M, Schwarz RS, and Plickert G. 2010. Migration and differentiation potential of stem cells in the cnidarian Hydractinia analysed in eGFP-transgenic animals and chimeras. Dev Biol 348:120-129. 10.1016/j.ydbio.2010.08.017

Leclere L, Jager M, Barreau C, Chang P, Le Guyader H, Manuel M, and Houliston E. 2012. Maternally localized germ plasm mRNAs and germ cell/stem cell formation in the cnidarian Clytia. Dev Biol 364:236-248. 10.1016/j.ydbio.2012.01.018

Leevers SJ, and McNeill H. 2005. Controlling the size of organs and organisms. Curr Opin Cell Biol 17:604-609. 10.1016/j.ceb.2005.09.008

Loewith R, and Hall MN. 2011. Target of rapamycin (TOR) in nutrient signaling and growth control. Genetics 189:1177-1201. 10.1534/genetics.111.133363

Miura S, and Kimura S. 1985. Jellyfish mesogloea collagen. Characterization of molecules as alpha 1 alpha 2 alpha 3 heterotrimers. J Biol Chem 260:15352-15356.

Miyake H, Iwao K, and Kakinuma Y. 1997. Life history and environment of Aurelia aurita. South Pacific Study 17:273-285.

Momose T, Derelle R, and Houliston E. 2008. A maternally localised Wnt ligand required for axial patterning in the cnidarian Clytia hemisphaerica. Development 135:2105-2113. 10.1242/dev.021543

Muller WA, Teo R, and Frank U. 2004. Totipotent migratory stem cells in a hydroid. Dev Biol 275:215-224. 10.1016/j.ydbio.2004.08.006

Peer] reviewing PDF | (2019:03:36215:1:1:REVIEW 5 Jul 2019) 
535

536

537

538

539

540

541

542

543

544

545

546

547

548

549

550

551

552

553

554

555

556

557

558

559

560

561

562

563

564

565

566

567

568

569

570

571

572

573

574

575

576

577

578

579

580

O'Brien LE, Soliman SS, Li X, and Bilder D. 2011. Altered modes of stem cell division drive adaptive intestinal growth. Cell 147:603-614. 10.1016/j.cell.2011.08.048

Pellettieri J, and Sanchez Alvarado A. 2007. Cell turnover and adult tissue homeostasis: from humans to planarians. Annu Rev Genet 41:83-105. 10.1146/annurev.genet.41.110306.130244

Penzo-Mendez AI, and Stanger BZ. 2015. Organ-Size Regulation in Mammals. Cold Spring Harb Perspect Biol 7:a019240. 10.1101/cshperspect.a019240

Quiroga Artigas G, Lapebie P, Leclere L, Takeda N, Deguchi R, Jekely G, Momose T, and Houliston E. 2018. A gonad-expressed opsin mediates light-induced spawning in the jellyfish Clytia. Elife 7. 10.7554/eLife.29555

Ragkousi K, Marr K, McKinney S, Ellington L, and Gibson MC. 2017. Cell-Cycle-Coupled Oscillations in Apical Polarity and Intercellular Contact Maintain Order in Embryonic Epithelia. Curr Biol 27:1381-1386. 10.1016/j.cub.2017.03.064

Salic A, and Mitchison TJ. 2008. A chemical method for fast and sensitive detection of DNA synthesis in vivo. Proc Natl Acad Sci U S A 105:2415-2420. 10.1073/pnas.0712168105

Schiaffino S, Dyar KA, Ciciliot S, Blaauw B, and Sandri M. 2013. Mechanisms regulating skeletal muscle growth and atrophy. FEBS J 280:4294-4314. 10.1111/febs.12253

Schmid V, and Alder H. 1984. Isolated, mononucleated, striated muscle can undergo pluripotent transdifferentiation and form a complex regenerate. Cell 38:801-809.

Schmid V, Alder H, Plickert G, and Weber C. 1988. Transdifferentiation from striated muscle of medusae in vitro. Cell Differ Dev 25 Suppl:137-146.

Schmid V, Wydler M, and Alder H. 1982. Transdifferentiation and regeneration in vitro. Dev Biol 92:476-488.

Schuchert P. 2007. The European athecate hydroids and their medusae (Hydrozoa, Cnidaria): Filifera Part 2. Revue Suisse De Zoologie 114:195-396. DOI 10.5962/bhl.part.80395

Schuchert P. 2019. World Hydrozoa Database. Accessed at http://www.marinespecies.org/hydrozoa.

Suga H, Tschopp P, Graziussi DF, Stierwald M, Schmid V, and Gehring WJ. 2010. Flexibly deployed Pax genes in eye development at the early evolution of animals demonstrated by studies on a hydrozoan jellyfish. Proc Natl Acad Sci U S A 107:14263-14268. 10.1073/pnas.1008389107

Szczepanek S, Cikala M, and David CN. 2002. Poly-gamma-glutamate synthesis during formation of nematocyst capsules in Hydra. J Cell Sci 115:745-751.

Takeda N, Deguchi R, and Itabashi T. 2018a. Reproductive Strategies in Marine Hydrozoan Jellyfish: Sexual Medusae and Asexual Polyps. Reproductive and Developmental Strategies Diversity and Commonality in Animals (Springer, Tokyo):157-174.

Takeda N, Kon Y, Quiroga Artigas G, Lapebie P, Barreau C, Koizumi O, Kishimoto T, Tachibana K, Houliston E, and Deguchi R. 2018b. Identification of jellyfish neuropeptides that act directly as oocyte maturation-inducing hormones. Development 145. 10.1242/dev.156786

Takeda N, Nakajima Y, Koizumi O, Fujisawa T, Takahashi T, Matsumoto M, and Deguchi R. 2013. Neuropeptides trigger oocyte maturation and subsequent spawning in the hydrozoan jellyfish Cytaeis uchidae. Mol Reprod Dev 80:223-232. $10.1002 / \operatorname{mrd} .22154$

Peer] reviewing PDF | (2019:03:36215:1:1:REVIEW 5 Jul 2019) 
581 Technau U, and Steele RE. 2011. Evolutionary crossroads in developmental biology:

$582 \quad$ Cnidaria. Development 138:1447-1458. 10.1242/dev.048959

583 Thongrod S, Wanichanon C, Kankuan W, Siangcham T, Phadngam S, Morani F, Isidoro C, and $584 \quad$ Sobhon P. 2018. Autophagy-Associated Shrinkage of the Hepatopancreas in Fasting

585

586

587

588

589

590

591

592

593

594

595

596

597

598

599

Male Macrobrachium rosenbergii Is Rescued by Neuropeptide F. Front Physiol 9:613. 10.3389/fphys.2018.00613

Tracy K, and Baehrecke EH. 2013. The role of autophagy in Drosophila metamorphosis.

Curr Top Dev Biol 103:101-125. 10.1016/B978-0-12-385979-2.00004-6

van Dam TJ, Zwartkruis FJ, Bos JL, and Snel B. 2011. Evolution of the TOR pathway.J Mol Evol 73:209-220. 10.1007/s00239-011-9469-9

Wang W, Rigueur D, and Lyons KM. 2014. TGFbeta signaling in cartilage development and maintenance. Birth Defects Res C Embryo Today 102:37-51. 10.1002/bdrc.21058

Weber C. 1981. Structure, histochemistry, ontogenetic development, and regeneration of the ocellus of Cladonema radiatum dujardin (cnidaria, hydrozoa, anthomedusae). J Morphol 167:313-331. 10.1002/jmor.1051670306

600

601

Figure 1. Cell proliferation patterns in young Cladonema medusa

602

(A) Young medusa of Cladonema pacificum. (B) Sexually-matured medusa of

603

Cladonema pacificum. (C) The scheme of Cladonema medusa development. (D-K, N-

604

O) Distribution of S-phase cells in the Cladonema pacificum medusa (1 day old)

605

revealed by EdU staining (20 $\mu \mathrm{M}, 24 \mathrm{hr}$ incubation). (D-E) Distribution of S-phase cells

606

$(E d U+)$ in a medusa whole body. (F-G) Distribution of S-phase cells (EdU+) in a

607

medusa manubrium. $(\mathrm{H}-\mathrm{I})$ Distribution of S-phase cells $(\mathrm{EdU}+)$ in a medusa exumbrella.

608 (J-K) Distribution of S-phase cells (EdU+) in a medusa subumbrella. (L-M) Mitotic cells

609 detected by anti-PH3 in a medusa umbrella (8 day old). (N-O) Distribution of S-phase

610 cells $(\mathrm{EdU}+)$ in medusa tentacles. $(\mathrm{P})$ Mitotic cells $(\mathrm{PH} 3+)$ in medusa tentacle bulbs $(1$

611 day old). Arrows indicate EdU-positive ( $\mathrm{H}-\mathrm{K})$ and $\mathrm{PH} 3$-positive $(\mathrm{L}, \mathrm{P})$ cells, respectively.

612

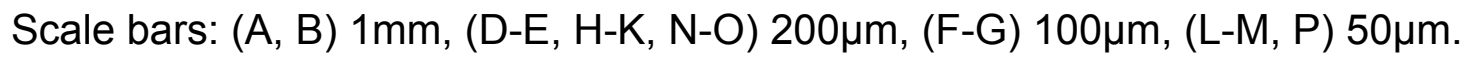

613

614 Figure 2. Cell proliferation patterns in sexually mature Cladonema medusa

615 (A-H) Distribution of S-phase cells in the Cladonema pacificum medusa (45 day old)

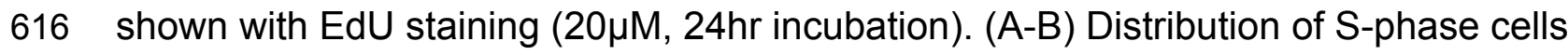

$617(\mathrm{EdU}+)$ in a medusa exumbrella. (C-D) Distribution of S-phase cells $(\mathrm{EdU}+)$ in a medusa 
618 subumbrella. (E-F) Distribution of S-phase cells (EdU+) in medusa tentacles. $(\mathrm{G}-\mathrm{H})$

619 Distribution of S-phase cells (EdU+) in a medusa manubrium. Arrows indicate EdU-

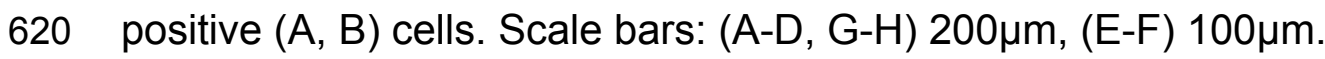

621

\section{Figure 3. Cell proliferation is necessary for body-size growth}

623

(A) Cladonema pacificum newborn medusa (0 day old). (B) Cladonema pacificum

624 juvenile medusa (8 day old). (C) Quantification of umbrella size in control and starved

625 medusae. Control medusae were fed every other day. Error bar: SD. Unpaired two-

626 tailed $t$-test. Day $1 \mathrm{t}(36)=4.545$, day $3 \mathrm{t}(36)=9.888$, day $6 \mathrm{t}(36)=12.56,{ }^{* * *} p<0.0001$.

627 (D-G) Distribution of S-phase cells in control medusa and starved medusa with EdU 628 staining $(20 \mu \mathrm{M}, 24 \mathrm{hr}$ incubation). (H) Quantification of the number of S-phase cells

$629(\mathrm{EdU}+)$ in control and starved medusae. Unpaired two-tailed $t$-test. ${ }^{*} p<0.05(p=0.0127)$,

$630 \mathrm{t}=3.194 \mathrm{df}=8$. ( $\mathrm{I}-\mathrm{L})$ Distribution of S-phase cells in medusa of control (HU-) and

631 hydroxyurea $(\mathrm{HU}+)$ treatment detected by EdU staining $(20 \mu \mathrm{M}, 24 \mathrm{hr})$. No S-phase cells

632 were detected in $\mathrm{HU}+$ medusae. (M) Quantification of body size in control and in $\mathrm{HU}$

633 conditions. HU suppresses body-size growth. HU-: control medusae incubated in ASW,

$634 \mathrm{HU}+$ : medusae incubated in HU 10mM ASW. Both HU+ and HU- were fed every other

635 day. Error bar: SD. Unpaired two-tailed $t$-test. Day $1 \mathrm{t}(93)=3.561$, day $2 \mathrm{t}(90)=4.079$, day

$6363 \mathrm{t}(81)=3.657$, day $5 \mathrm{t}(85)=6.329$, day $6 \mathrm{t}(52)=4.105$, day $7 \mathrm{t}(79)=7.319$, day 8

$637 \mathrm{t}(71)=9.201$, day $9 \mathrm{t}(59)=8.826,{ }^{* * *} p<0.0005,{ }^{* * * *} p<0.0001$. Scale bars: (A-B) $1 \mathrm{~mm}$,

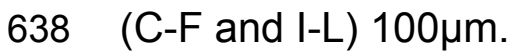

639

640 Figure 4. Cell proliferation is necessary for tentacle morphogenesis

641 (A) Control (HU-) medusa incubated in ASW for 9 days. The picture shows the

642 representative image of medusae with three branched tentacles. (B) The medusa

643 incubated in $10 \mathrm{mM} \mathrm{HU}(\mathrm{HU}+)$ ASW for 9 days. The picture shows the representative

644 image of medusae with one branched tentacle. (C) Quantification of branching numbers

645 per tentacle at Day 0 and Day 9. HU+: $n=313$, HU- condition: $n=199$. Error bars: SD.

646 Unpaired two-tailed $t$-test. $\mathrm{t}(510)=54.49,{ }^{* * * *} p<0.0001$. (D-G) Nematocytes in tentacles

647 labeled by DAPI (poly- $Y$-glutamate) in the 8 day old medusa incubated in ASW (HU-) or

$64810 \mathrm{mM} \mathrm{HU}$ ASW $(\mathrm{HU}+)$. Arrowheads indicate empty nematocysts. $(\mathrm{H})$ The proportion of 
649 empty nematocysts in $\mathrm{HU}$ - and $\mathrm{HU}+$ medusa. HU+: $n=19$, HU-: $n=18$. Unpaired two650 tailed $t$-test. $\mathrm{t}(31)=2.869,{ }^{* *} p<0.01(p=0.0074)$. Scale bar: $(D-G) 50 \mu \mathrm{m}$.

651

652 Figure 5. Cell proliferation is necessary for tentacle regeneration

653 (A-D) Tentacle regenerative processes after amputation in an adult medusa. Series of 654 pictures show the growing tentacle over 4 days. $(\mathrm{E}-\mathrm{F})$ Mitotic cells $(\mathrm{PH} 3+)$ in tentacle 655 bulbs of the unremoved control and the dissected medusa. Arrowheads indicate PH3656 positive cells. (G) Quantification of proliferative cells in tentacle bulbs for control and 657 after amputation. Control: $n=26$, Amputation: $n=11$. error bar: SD. Unpaired two-tailed $t$ 658 test. $\mathrm{t}(35)=6.246,{ }^{* * * *} p<0.0001$. $(\mathrm{H})$ Quantification of tentacle length after amputation in 659 control (HU-) and 10mM HU treatment (HU+). Unpaired two-tailed $t$-test. Day 1 660 661 $662100 \mu \mathrm{m}$.

663

664

665

666

Figure 6. Cell proliferation patterns across different hydrozoan jellyfish $\mathrm{t}(46)=9.227$, day $2 \mathrm{t}(46)=10.29$, day $3 \mathrm{t}(46)=14.1$, day $4 \mathrm{t}(46)=20.5$, day $5 \mathrm{t}(46)=22.49$, day $6 \mathrm{t}(45)=17.11$, day $7 \mathrm{t}(45)=15.36,{ }^{* * * *} p<0.0001$. Scale bars: $(A-D) 1 \mathrm{~mm},(E-F)$

(A) Distribution of S-phase cells in the Cytaeis uchidae medusa (30 day old) shown with EdU staining (EdU: $20 \mu \mathrm{M}, 24 \mathrm{hr}$ ). (B) Distribution of S-phase cells (EdU+) in Cytaeis medusa (11 day old). (C) Mitotic cells (PH3+) in the umbrella of Cytaeis medusa (30 day 668 old). (D) Mitotic cells in Cytaeis medusa tentacle bulbs (30 day old). (E-F) Distribution of S-phase cells (EdU+) in the Rathkea octpunctata juvenile medusa (EdU: $20 \mu \mathrm{M}, 24 \mathrm{hr}$ ).

670 $(\mathrm{G})$ Mitotic cells $(\mathrm{PH} 3+)$ in a manubrium of Rathkea juvenile medusa. $(\mathrm{H})$ Mitotic cells

671 (PH3+) in Rathkea juvenile medusa tentacles. Arrows indicate PH3-positive mitotic 672 cells. Scale bars: $100 \mu \mathrm{m}$.

673

674 Figure S1. Cell proliferation patterns in young Cladonema medusa

675 (A-D) Distribution of S-phase cells in the Cladonema pacificum medusa (1 day old)

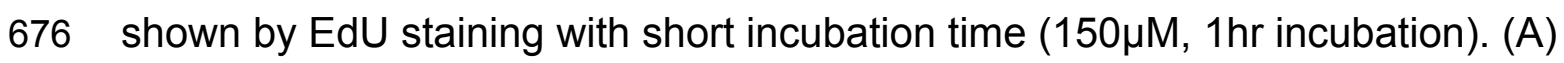
677 Distribution of S-phase cells (EdU+) in a whole medusa body. (B) Distribution of S678 phase cells (EdU+) in a medusa manubrium. (C) Distribution of S-phase cells (EdU+) in 
679 a medusa umbrella. (D) Distribution of S-phase cells (EdU+) in medusa tentacles. Scale 680 bar: (A, C) $200 \mu \mathrm{m},(B, D) 100 \mu \mathrm{m}$.

681

682 Figure S2. Spatial distribution of mitotic cells in tentacle bulbs of Cladonema 683 medusa

684 (A, B) Cross sections of medusa tentacle bulbs. (A) Mitotic cells (PH3+) located in 685 ectoderm in medusa tentacle bulbs (70 days old). (B) Mitotic cells ( $\mathrm{PH} 3+$ ) located in 686 ectoderm in medusa tentacle bulbs (30 days old). Scale bars: (A-B) $50 \mu \mathrm{m}$.

687

688 Figure S3. The effects of HU treatment

689 (A) Cladonema pacificum medusa (2 days old) before feeding (left image) and 690 Cladonema pacificum medusa (2 days old) after feeding (right image). (B) Cladonema 691 pacificum medusa (2 days old) with $48 \mathrm{hr} \mathrm{HU}$ treatment before feeding (left image) and 692 Cladonema pacificum medusa (2 days old) with $48 \mathrm{hr} \mathrm{HU}$ treatment after feeding (right 693 image). (C) Quantification of the number of tentacle branching in control and HU-treated 694 medusa, with HU washed off, after $48 \mathrm{hr}$ treatment. Error bar: SD. Scale bars: (A, B) $6951 \mathrm{~mm}$.

696

697 


\section{Figure 1}

Cell proliferation patterns in young Cladonema medusa

(A) Young medusa of Cladonema pacificum. (B) Sexually-matured medusa of Cladonema pacificum. (C) The scheme of Cladonema medusa development. (D-K, N-O) Distribution of Sphase cells in the Cladonema pacificum medusa ( 1 day old) revealed by EdU staining $(20 \mu \mathrm{M}$, 24hr incubation). (D-E) Distribution of S-phase cells (EdU+) in a medusa whole body. (F-G) Distribution of S-phase cells (EdU+) in a medusa manubrium. (H-I) Distribution of S-phase cells (EdU+) in a medusa exumbrella. (J-K) Distribution of S-phase cells (EdU+) in a medusa subumbrella. (L-M) Mitotic cells detected by anti-PH3 in a medusa umbrella (8 day old). ( $\mathrm{N}-\mathrm{O}$ ) Distribution of S-phase cells ( $(\mathrm{EdU}+$ ) in medusa tentacles. (P) Mitotic cells ( $\mathrm{PH} 3+$ ) in medusa tentacle bulbs ( 1 day old). Arrows indicate EdU-positive (H-K) and PH3-positive (L, P) cells,

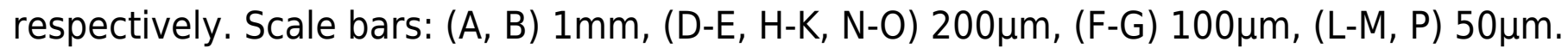



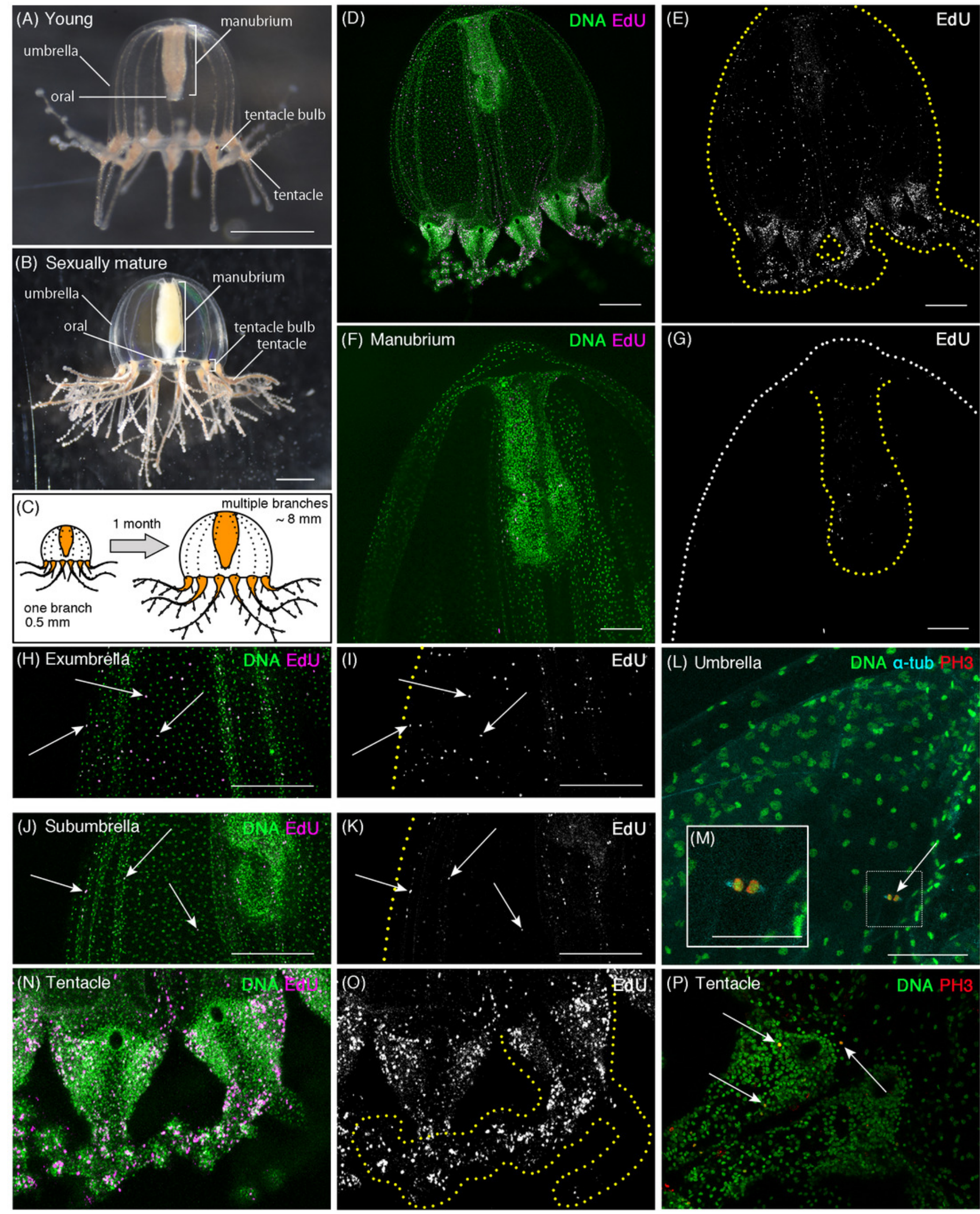

(P) Tentacle

DNA PH3

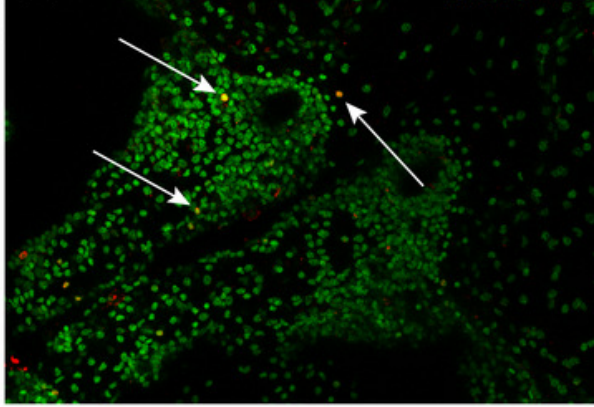




\section{Figure 2}

Cell proliferation patterns in sexually mature Cladonema medusa

(A-H) Distribution of S-phase cells in the Cladonema pacificum medusa (45 day old) shown

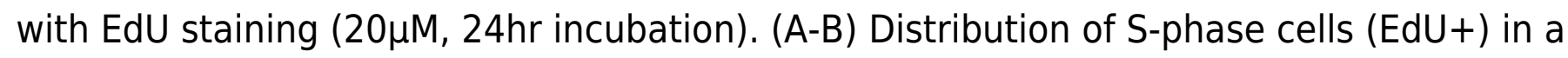
medusa exumbrella. (C-D) Distribution of S-phase cells (EdU+) in a medusa subumbrella. (EF) Distribution of S-phase cells (EdU+) in medusa tentacles. (G-H) Distribution of S-phase cells (EdU+) in a medusa manubrium. Arrows indicate EdU-positive (A, B) cells. Scale bars: (A-D, G-H) $200 \mu \mathrm{m}$, (E-F) $100 \mu \mathrm{m}$. 

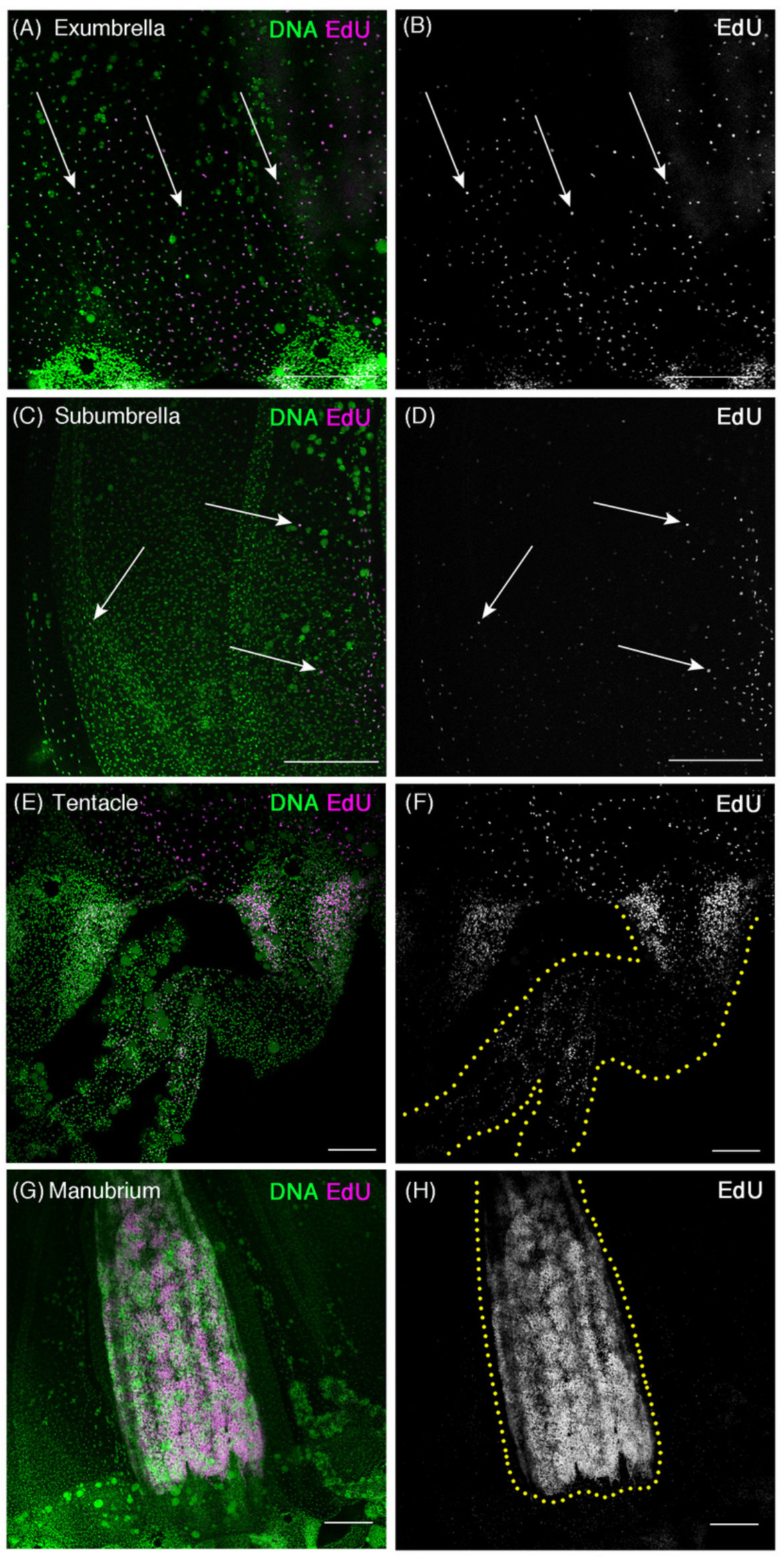

Peer) reviewing PDF | (2019:03:36215:1:1:REVIEW 5 Jul 2019) 


\section{Figure 3}

Cell proliferation is necessary for body-size growth

(A) Cladonema pacificum newborn medusa (0 day old). (B) Cladonema pacificum juvenile medusa (8 day old). (C) Quantification of umbrella size in control and starved medusae. Control medusae were fed every other day. Error bar: SD. Unpaired two-tailed $t$-test. Day 1 $\mathrm{t}(36)=4.545$, day $3 \mathrm{t}(36)=9.888$, day $6 \mathrm{t}(36)=12.56,{ }^{* * * *} p<0.0001$. (D-G) Distribution of Sphase cells in control medusa and starved medusa with EdU staining $(20 \mu \mathrm{M}, 24 \mathrm{hr}$ incubation). (H) Quantification of the number of S-phase cells (EdU+) in control and starved medusae. Unpaired two-tailed $t$-test. ${ }^{*} p<0.05(p=0.0127), t=3.194 \mathrm{df}=8$. (I-L) Distribution of S-phase cells in medusa of control (HU-) and hydroxyurea $(\mathrm{HU}+)$ treatment detected by EdU

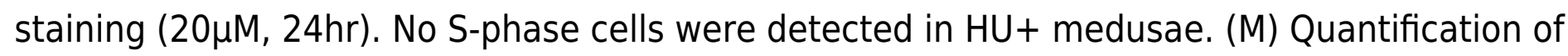
body size in control and in HU conditions. HU suppresses body-size growth. HU-: control medusae incubated in ASW, HU+: medusae incubated in HU 10mM ASW. Both HU+ and HUwere fed every other day. Error bar: SD. Unpaired two-tailed $t$-test. Day $1 \mathrm{t}(93)=3.561$, day 2 $\mathrm{t}(90)=4.079$, day $3 \mathrm{t}(81)=3.657$, day $5 \mathrm{t}(85)=6.329$, day $6 \mathrm{t}(52)=4.105$, day $7 \mathrm{t}(79)=7.319$, day $8 \mathrm{t}(71)=9.201$, day $9 \mathrm{t}(59)=8.826,{ }^{* * *} p<0.0005,{ }^{* * * *} p<0.0001$. Scale bars: (A-B) $1 \mathrm{~mm},(\mathrm{C}-\mathrm{F}$ and I-L) $100 \mu \mathrm{m}$. 

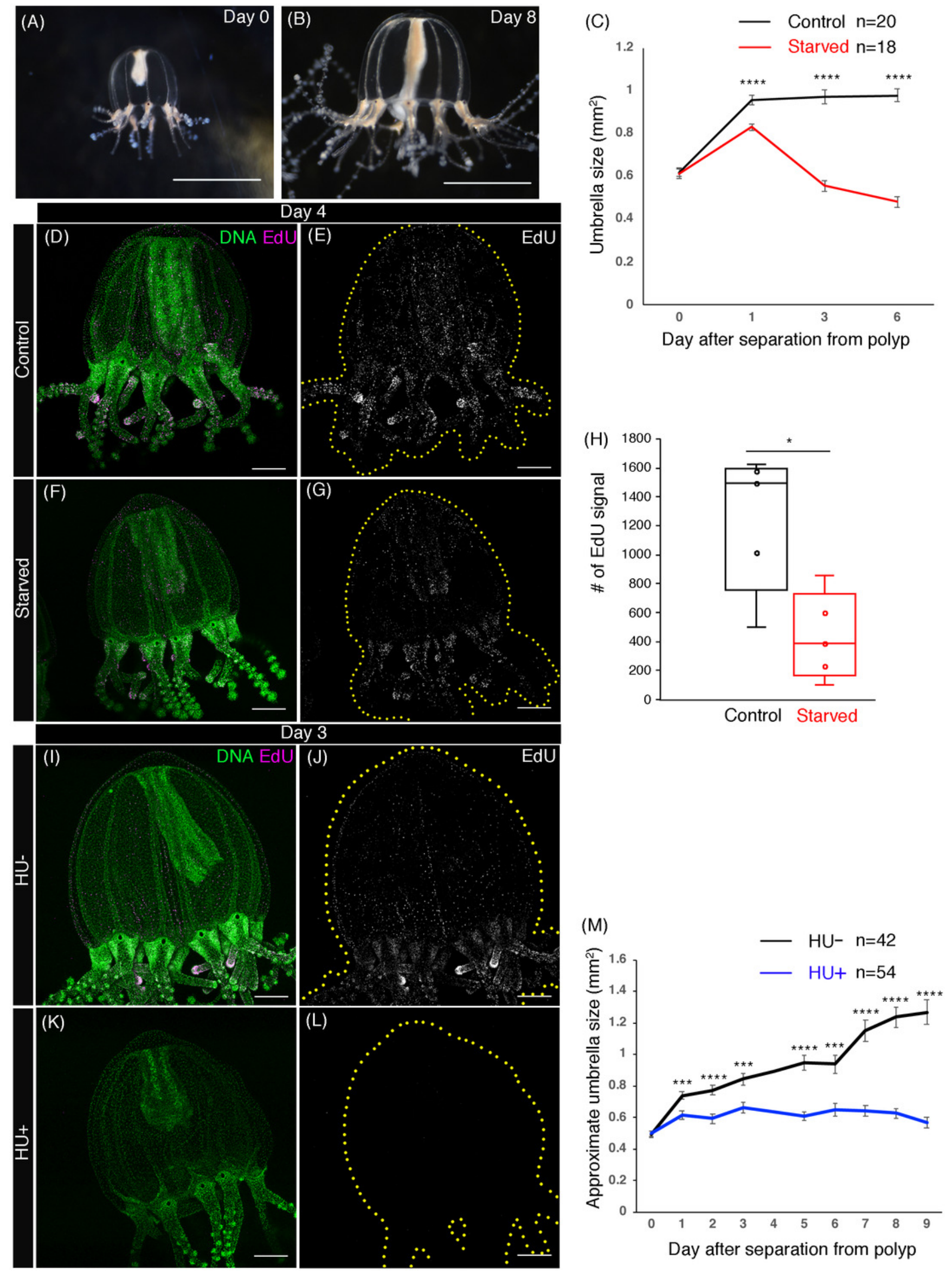

Peer) reviewing PDF | (2019:03:36215:1:1:REVIEW 5 Jul 2019) 


\section{Figure 4}

Cell proliferation is necessary for tentacle morphogenesis

(A) Control (HU-) medusa incubated in ASW for 9 days. The picture shows the representative image of medusae with three branched tentacles. (B) The medusa incubated in 10mM HU $(\mathrm{HU}+)$ ASW for 9 days. The picture shows the representative image of medusae with one branched tentacle. (C) Quantification of branching numbers per tentacle at Day 0 and Day 9. HUt: $n=313$, HU- condition: $n=199$. Error bars: SD. Unpaired two-tailed $t$-test. $t(510)=54.49$, $* * * p<0.0001$. (D-G) Nematocytes in tentacles labeled by DAPI (poly-y-glutamate) in the 8 day old medusa incubated in ASW (HU-) or 10mM HU ASW (HU+). Arrowheads indicate empty nematocysts. $(\mathrm{H})$ The proportion of empty nematocysts in $\mathrm{HU}$ - and $\mathrm{HU}+$ medusa. $\mathrm{HU}+: n=19$, HU-: $n=18$. Unpaired two-tailed $t$-test. $t(31)=2.869,{ }^{* *} p<0.01(p=0.0074)$. Scale bar: (D-G) $50 \mu \mathrm{m}$. 

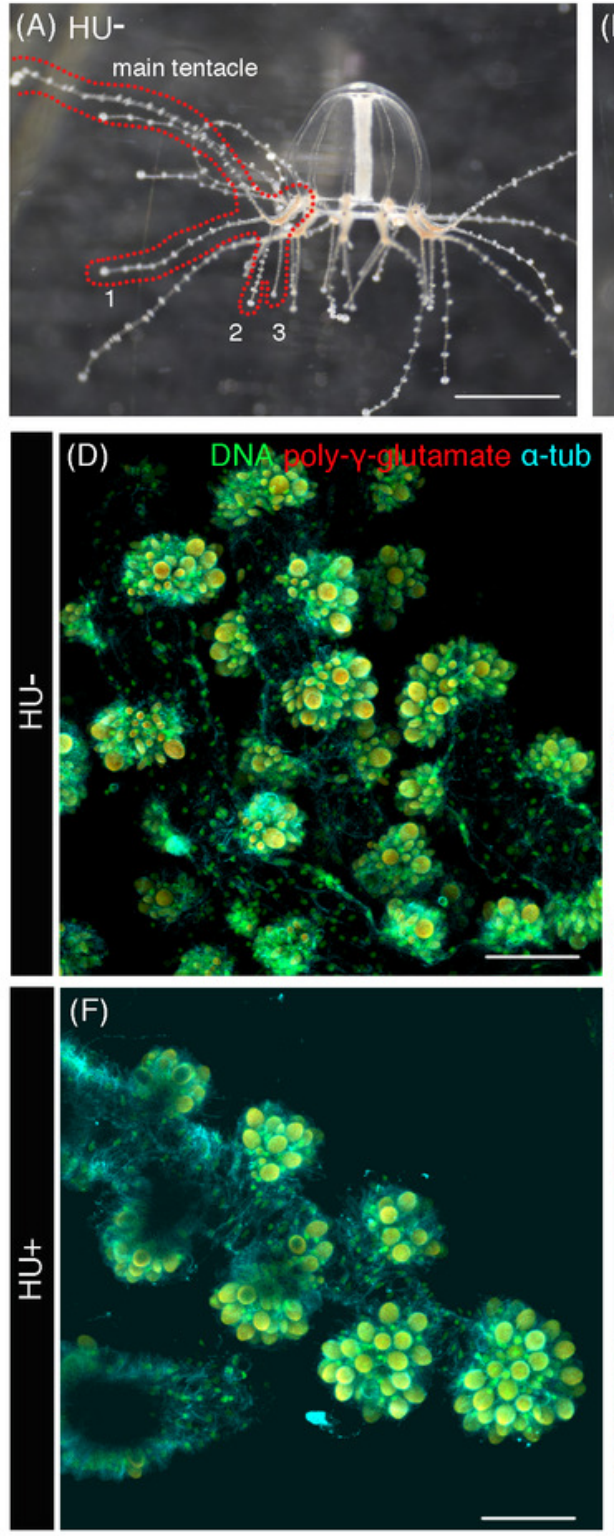
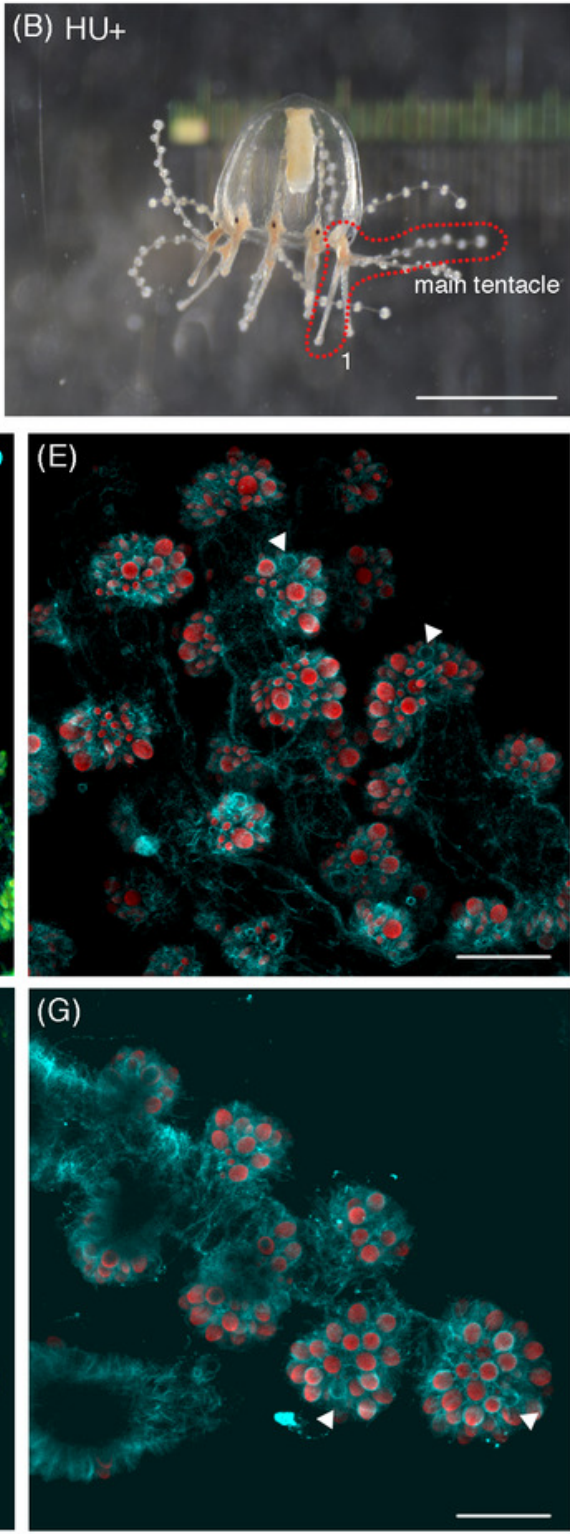
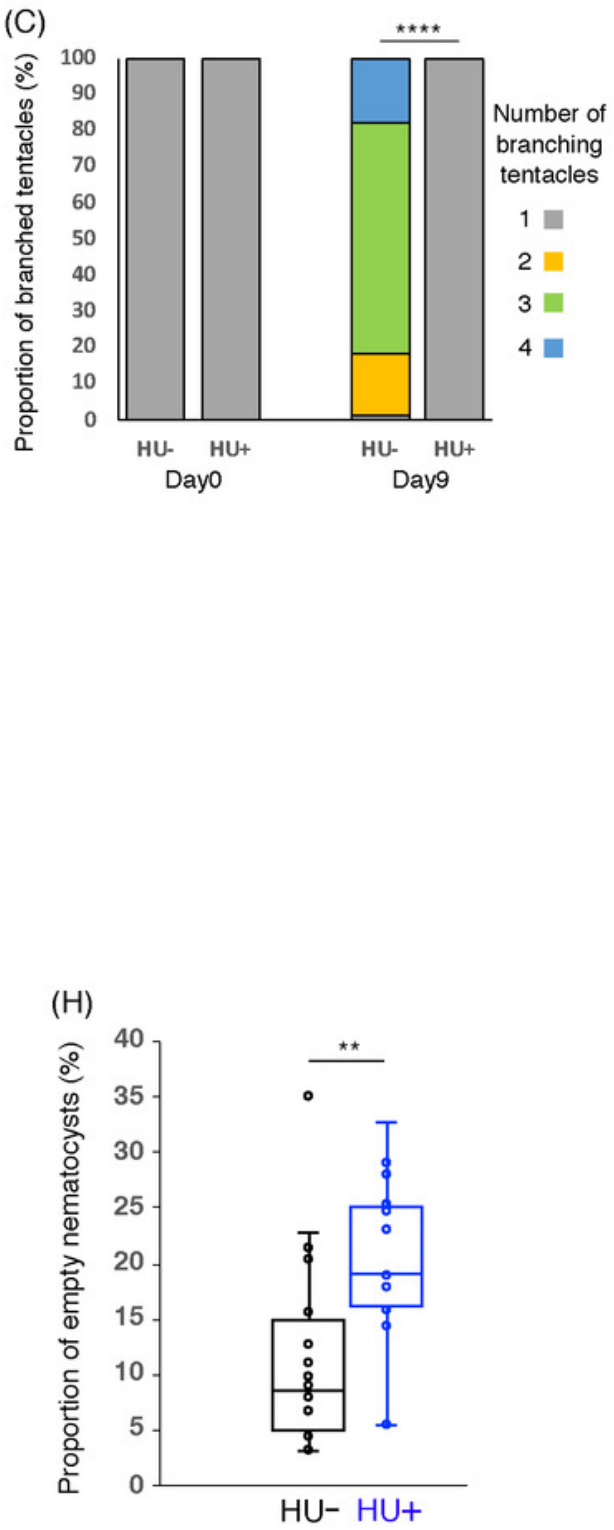


\section{Figure 5}

Cell proliferation is necessary for tentacle regeneration

(A-D) Tentacle regenerative processes after amputation in an adult medusa. Series of pictures show the growing tentacle over 4 days. (E-F) Mitotic cells (PH3+) in tentacle bulbs of the unremoved control and the dissected medusa. Arrowheads indicate PH3-positive cells. (G) Quantification of proliferative cells in tentacle bulbs for control and after amputation. Control: $n=26$, Amputation: $n=11$. error bar: SD. Unpaired two-tailed $t$-test. $\mathrm{t}(35)=6.246$, ${ }^{* * * *} p<0.0001$. (H) Quantification of tentacle length after amputation in control (HU-) and $10 \mathrm{mM} \mathrm{HU}$ treatment $(\mathrm{HU}+)$. Unpaired two-tailed $t$-test. Day $1 \mathrm{t}(46)=9.227$, day 2 $\mathrm{t}(46)=10.29$, day $3 \mathrm{t}(46)=14.1$, day $4 \mathrm{t}(46)=20.5$, day $5 \mathrm{t}(46)=22.49$, day $6 \mathrm{t}(45)=17.11$, day $7 \mathrm{t}(45)=15.36,{ }^{* * * *} p<0.0001$. Scale bars: (A-D) $1 \mathrm{~mm},(\mathrm{E}-\mathrm{F}) 100 \mu \mathrm{m}$. 

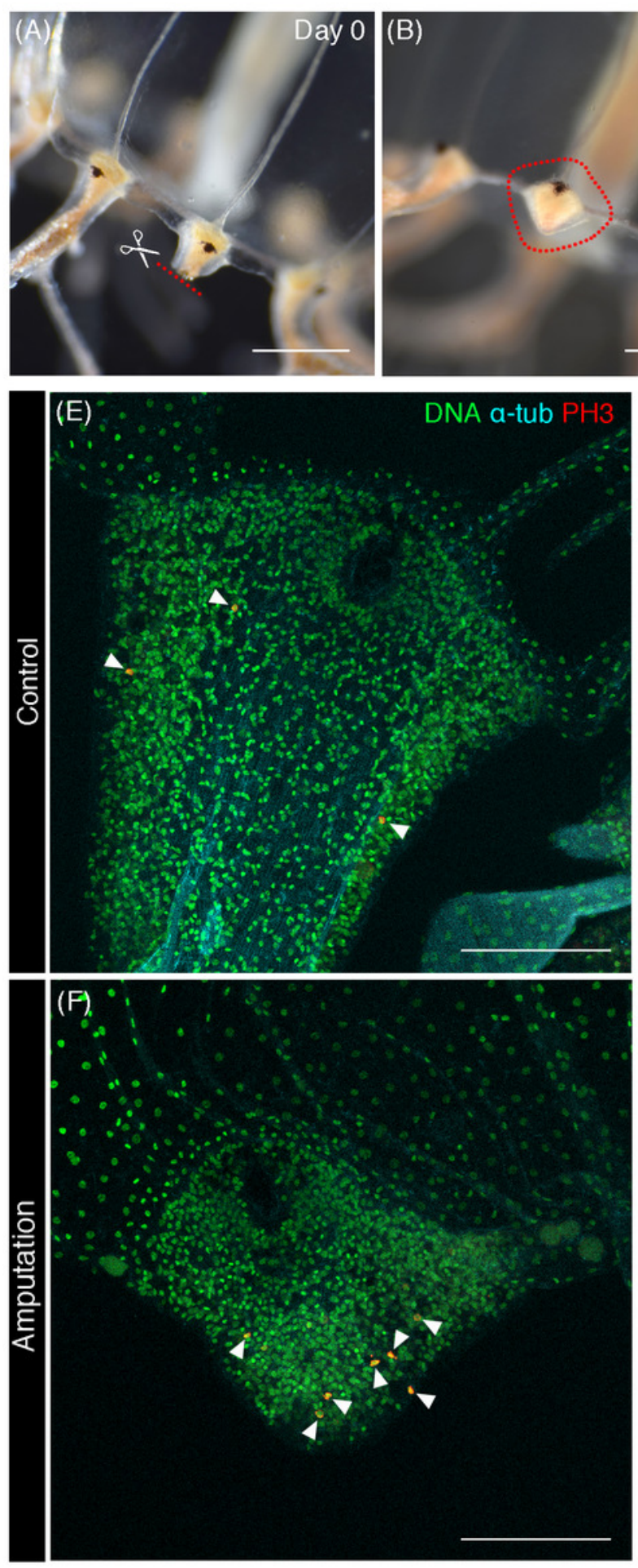
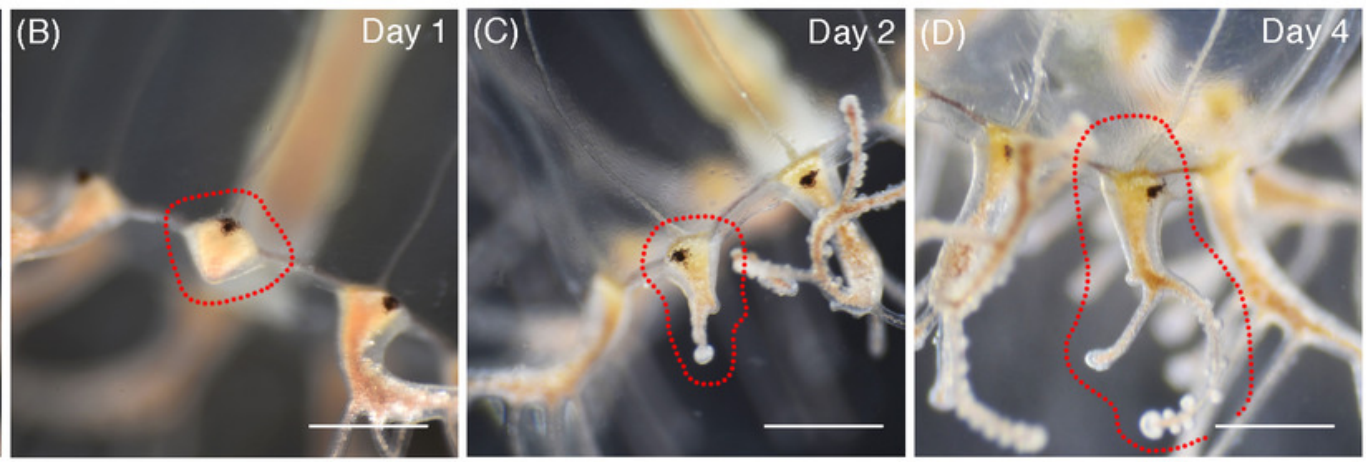

(G)

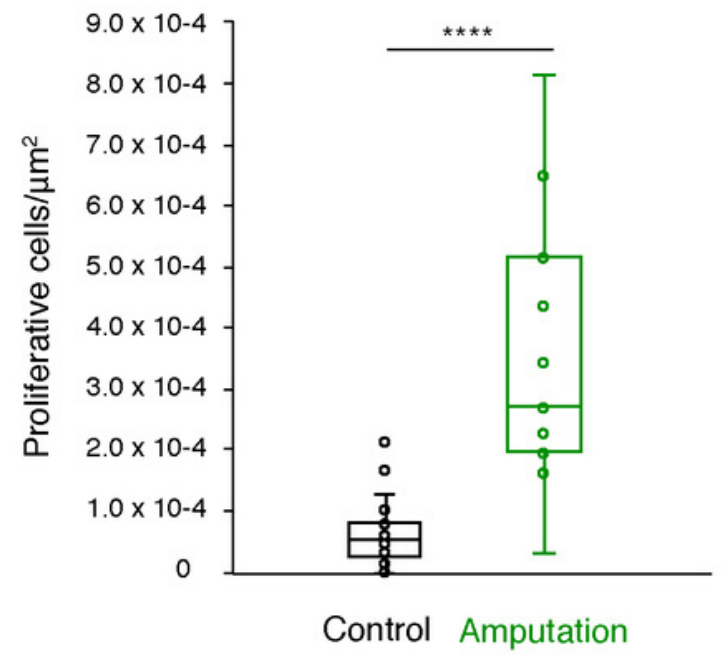

(H)

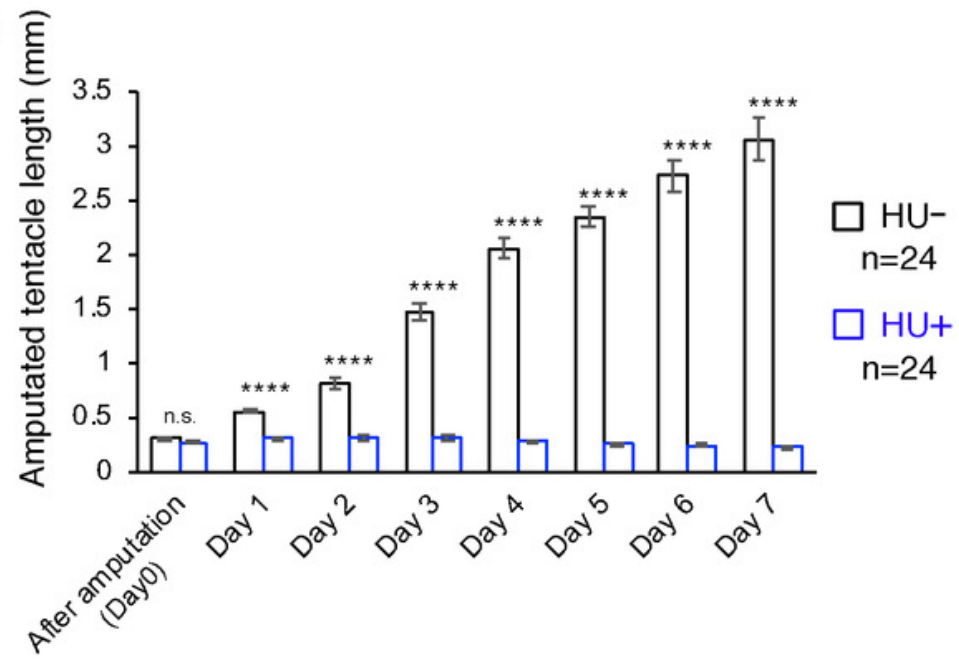




\section{Figure 6}

Cell proliferation patterns across different hydrozoan jellyfish

(A) Distribution of S-phase cells in the Cytaeis uchidae medusa (30 day old) shown with EdU

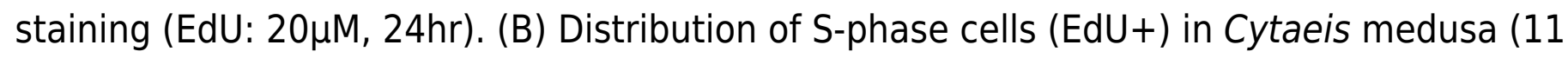
day old). (C) Mitotic cells (PH3+) in the umbrella of Cytaeis medusa (30 day old). (D) Mitotic cells in Cytaeis medusa tentacle bulbs (30 day old). (E-F) Distribution of S-phase cells (EdU+)

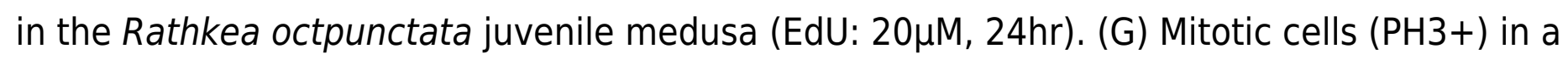
manubrium of Rathkea juvenile medusa. (H) Mitotic cells ( $\mathrm{PH} 3+$ ) in Rathkea juvenile medusa

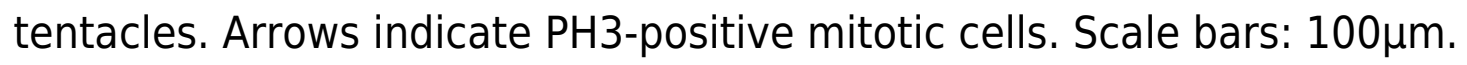


Cytaeis uchidae
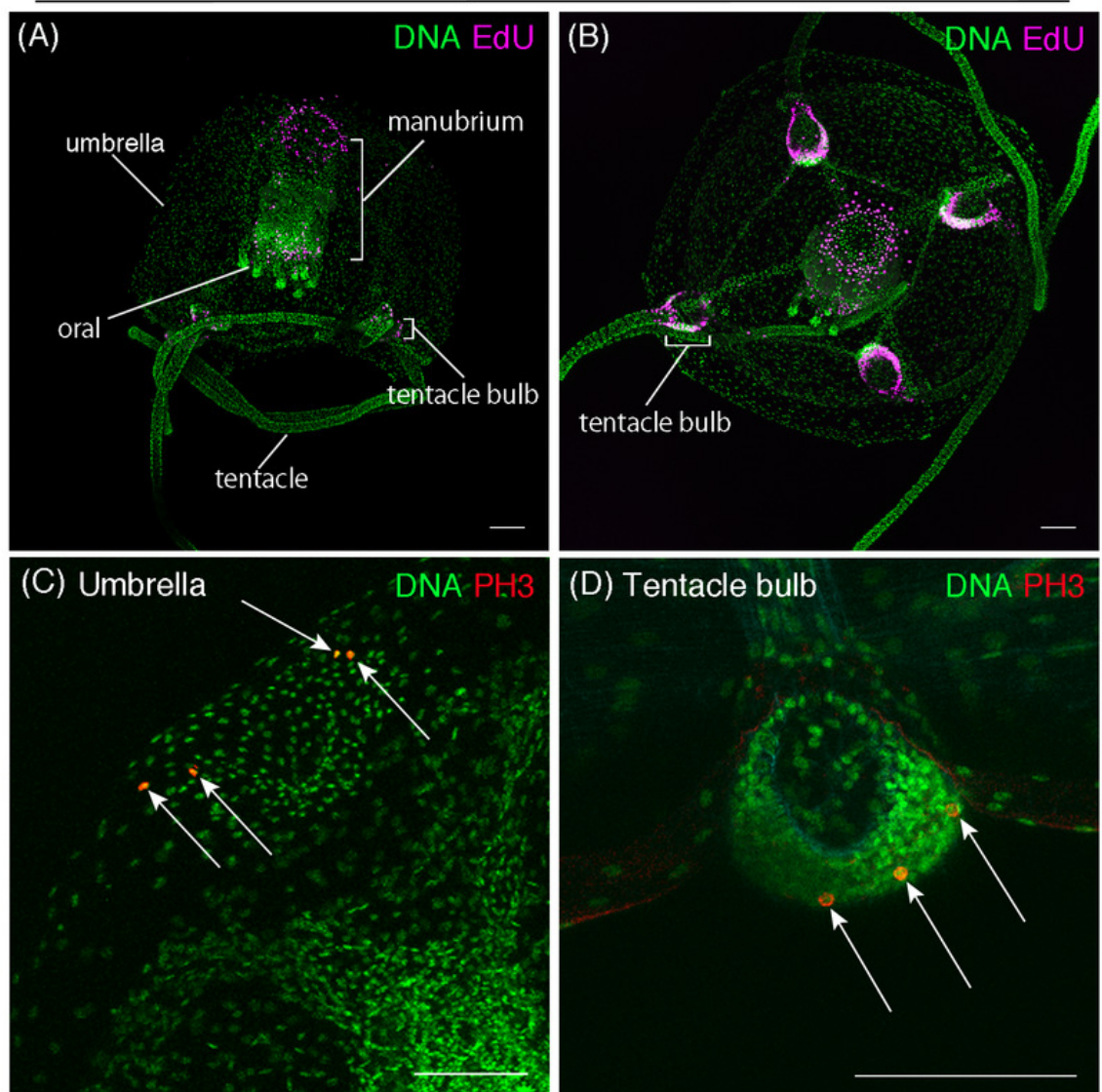

Rathkea octopunctata
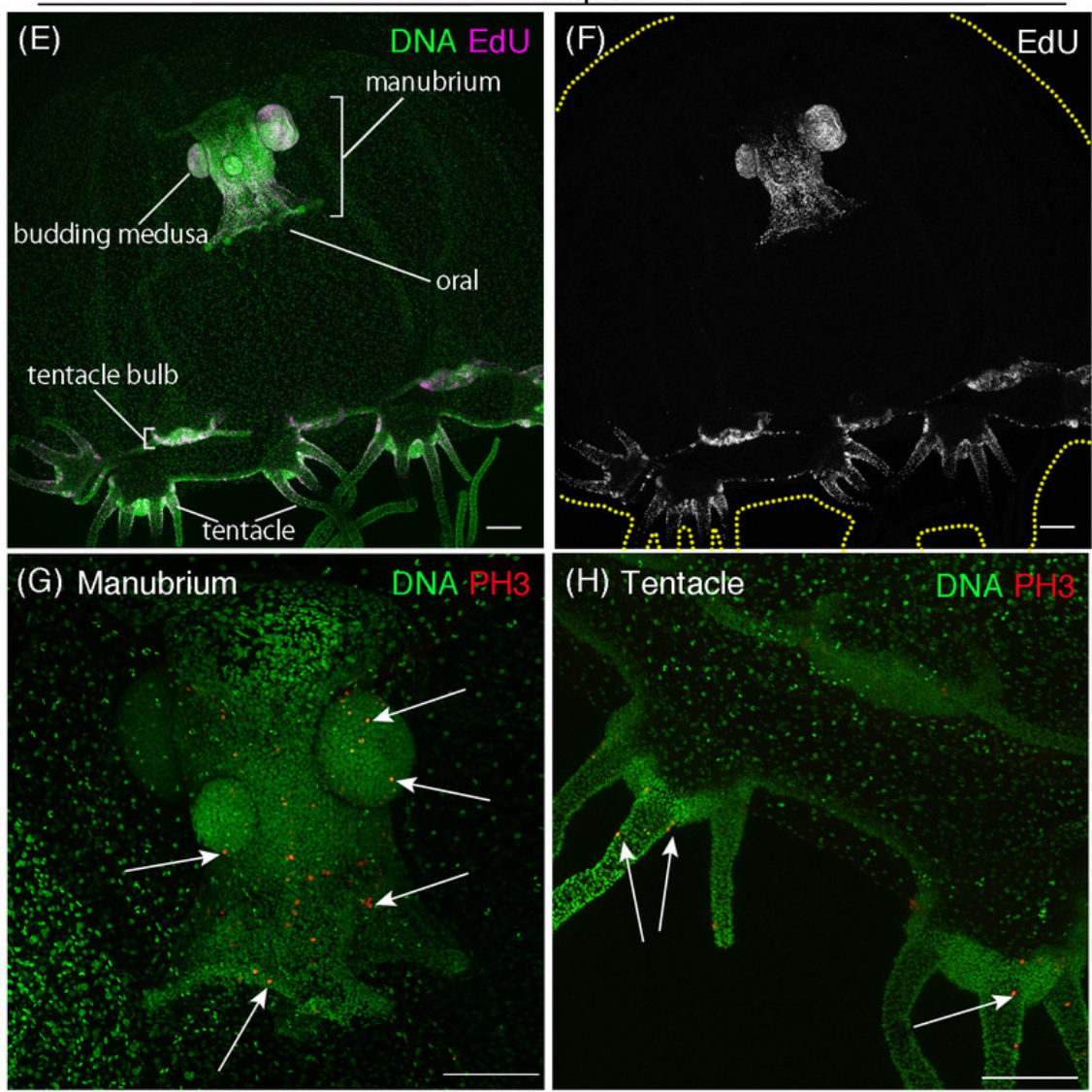

(H) Tentacle

DNA

Peer) reviewing PDF | (2019:03:36215:1:1:REVIEW 5 Jul 2019) 